\title{
INTEGRAÇÃO ENTRE OS MERCADOS DE BOI GORDO E DE CARNE BOVINA NAS REGIÕES CENTRO-OESTE E SUDESTE DO BRASIL
}

\author{
SERGIO DE ZEN
}

Orientador: Prof. Dr. GERALDO SANT' ANA DE CAMARGO BARROS

Dissertação apresentada à Escola Superior de Agricultura "Luiz de Queiroz", Universidade de São Paulo, para a obtenção do título de Mestre em Ciências, Área de Concentração: Economia Aplicada.

PIRACICABA

Estado de São Paulo - Brasil Janeiro - 1997 
Dados Internacionais de Catalogação na Publicação (CIP) DIVISĀO DE BIBLIOTECA E DOCUMENTAÇĀO - Campus "Luiz de Queiroz"/USP

De Zen, Sergio

Integração entre os mercados de boi gordo e de carne bovina nas regiōes centrooeste e sudeste do Brasil / Sergio De Zen. - - Piracicaba, 1997.

$81 \mathrm{p}$.

Dissertação (mestrado) - - Escola Superior de Agricultura Luiz de Queiroz, 1997. Bibliografia.

1. Brasil (região centro sul) 2. Carne bovina 3. Mercado 4. Pecuária de corte (aspecto econômico) 5. Preço 6. São Paulo (regiāo metropolitana) I. Titulo 


\section{INTEGRAÇÃO ENTRE OS MERCADOS DE BOI GORDO E DE CARNE BOVINA NAS REGIÕES CENTRO-OESTE E SUDESTE DO BRASIL}

Aprovado em: 01. 04.97.

Comissão Julgadora:

Prof. Dr. Geraldo S. Camargo Barros

ESALQ/USP

Dra. Mirian R. Piedade Bacchi

ESALQ/USP

Dr. Flávio Condé de Carvalho

IEA/SAA

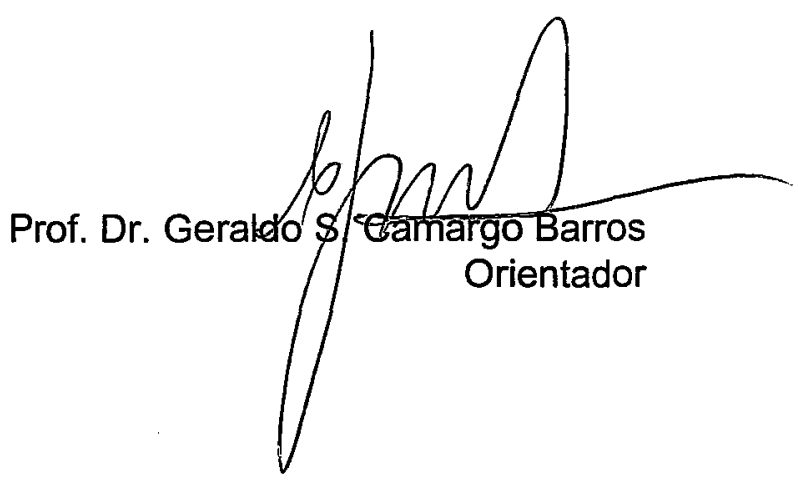


Aos meus pais,

Ugo e Brigida,

Ofereço.

A minha esposa,

Maria José,

dedico. 


\section{Agradecimentos}

Ao departamento de Economia e Sociologia Rural da Escola Superior de Agricultura "Luiz de Queiroz" - USP pela formação acadêmica e pessoal.

Ao Centro de Estudos Avançados em Economia Aplicada CEPEA/FEALQ/ESALQ pela estrutura, o apoio e o incentivo, e aos colegas de trabalho, em especial a Maria Aparecida Braghetta, Maria Aparecida Zani, Renata Schiavon, Luciane Cavaggioni Scafi e Valter Bertini Galan, pela compreensão, auxílio e respeito durante o desenvolvimento desta dissertação.

Ao CNPQ e a FEALQ que, através dos projetos Preços Agricolas e Indicadores de Preços da Pecuária de Corte, forneceram indispensável apoio financeiro para o desenvolvimento do trabalho.

A Bolsa de Mercadorias e Futuros - BM\&F que proporcionou os recursos para o levantamento dos dados, os quais que foram indispensáveis ao desenvolvimento do projeto de tese.

Aos professores Joaquim Bento de Souza Ferreira Filho e Ricardo Shirota, pelos conselhos as palavras de incentivo, a professora Heloísa Lee Burnqüist cuja cuidadosa leitura das quais surgiram valiosas observações e sugestões. 
A pesquisadora doutora Mirian Rumenos Piedade Bacchi cuja contribuição ao desenvolvimento do trabalho foi fundamental. Tanto pela sua capacidade técnica, que muito auxiliou na execusão do trabalho, quanto pelo seu exemplo de humildade, que valoriza ainda mais sua capacidade.

Um especial agradecimento ao Professor Geraldo Sant'Ana de Camargo Barros, que deu um sentido muito especial a palavra orientador, pois sua contribuição foi muito além das preciosas orientações técnicas. O exemplo de profissionalismo e de retidão de caráter são coisas que marcam a vida para sempre. Agradeço ainda a amizade, a compreenção e a confiança que recebi.

Agradeço aos meus pais, Ugo e Brigida, que nunca mediram sacrifícios para que eu atingisse os meus objetivos. Nos momentos difíceis sempre sabia que com eles poderia contar.

A minha esposa, amiga e companheira, Maria José, tenho tantos motivos para agradecer que acho mais sensato apenas lembrar que sempre foi a primeira incentivadora para o meu trabalho. 


\section{Sumário}

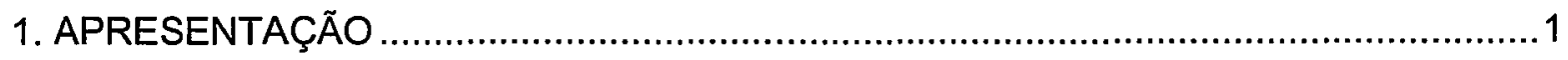

2. ASPECTOS GERAIS DA PRODUÇÃO E DA COMERCIALIZAÇÃO NA PECUÁRIA DE CORTE

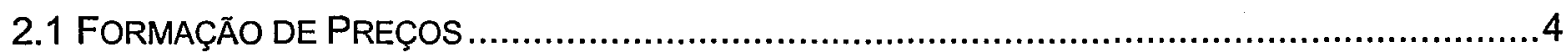

2.1.1 Localização dos Frigoríficos .......................................................................

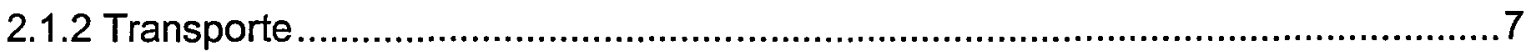

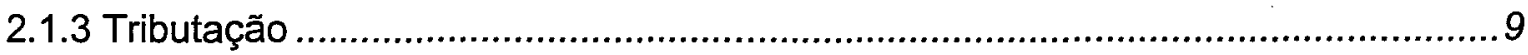

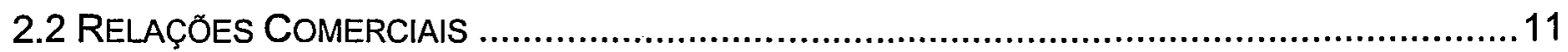

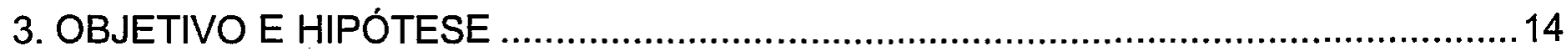

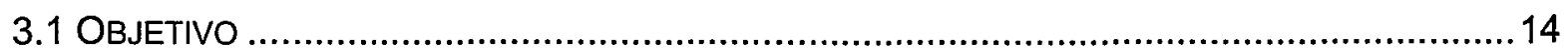

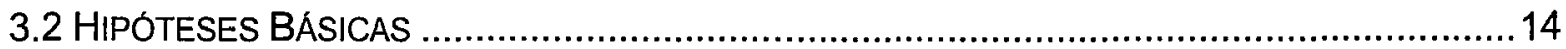

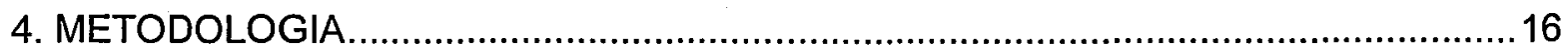

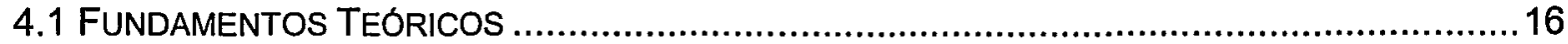

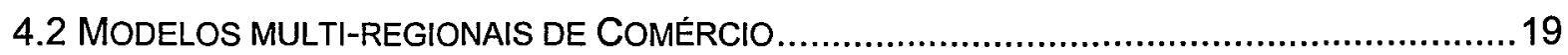

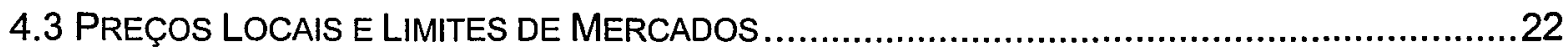

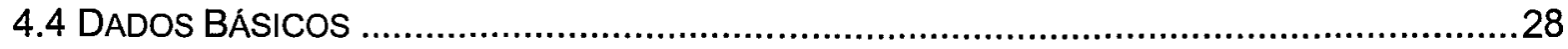




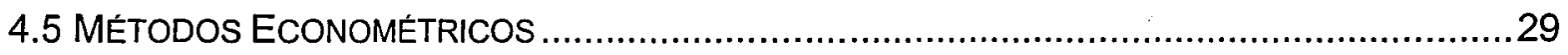

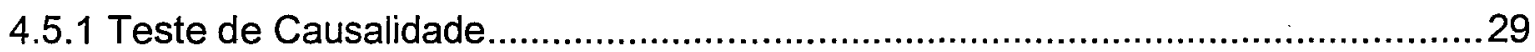

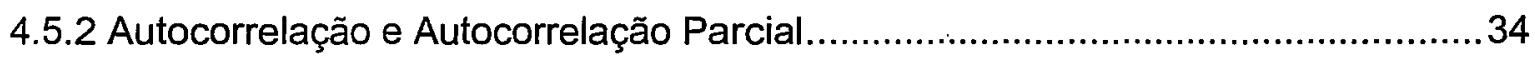

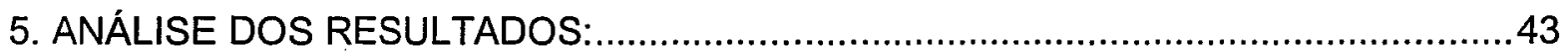

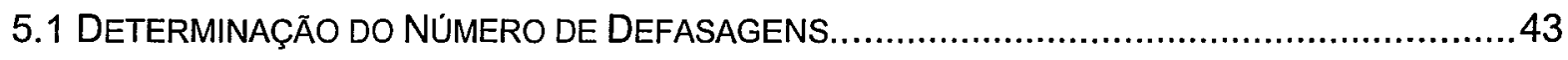

5.2 Resultados dos testes de Causalidade: Preços da Carne e os Preços de Bol GORDO

5.3 Resultados dos testes de Causalidade: Preços da ARRoba de Bol Gordo fora DO ESTADO DE SÃo PAULO E O INDICADOR DE PREÇOS ESALQ/BM\&F (SP) .......................60

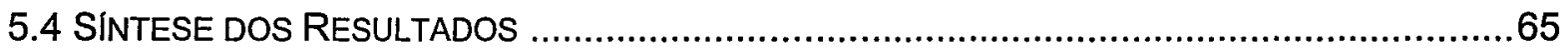

6. CONCLUSÃO

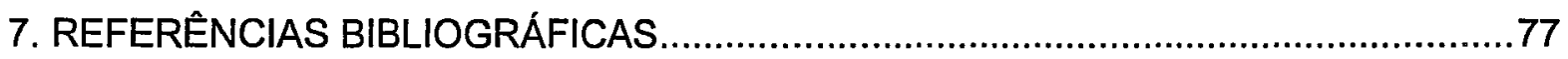




\section{Lista de Figuras}

FIgURA 1 : VOLUMES DE BOVINOS ABATIDOS PELOS FRIGORIFICOS EM CADA REGIÃO DE ACORDO COM DADOS REGISTRADOS NO SIF.

FIgURA 2 : COMÉRCIO REGIONAL SEM RECURSOS DE TRANSFERENCIA. (FONTE : BRESSLER \& KING, P.87, IN: BARROS, 1987, P 99) (FIGURA 4.1) 17

Figura 3: EFEITO do CUSTO de TRANSFERENCIA SOBRE O COMÉRCIO (FONTE: BRESSLER \& KING, P. 91 IN: BARROS, 1987. P. 103) (FIGURA 4.4) 19

FIGURA 4: INFORMAÇÕES BÁSICAS PARA MODELOS MULTI-REGIONAIS 20

FIgURA 5: SUPERFÍCIES DE CUSTO DE TRANSFERÊNCIAS (FONTE: BRESSLER \& KING, P112. IN: BARROS, 1987. P 123. ( FIG. 4.9 ). 23

FIGURA 6: LIMITE ENTRE DUAS ÁREAS DE MERCADO COM PREÇOS DIFERENTES. (FONTE: BRESSLER \& KING, P. 128. IN: BARROS, 1987. P. 129) (4.12) 24 


\section{Lista de Tabelas}

Tabela 1: Valor por quilometro para transporte de animais vivos - maio/95. 16

Tabela 2: Resultados dos testes de Akaike e Schwarz. 44

Tabela 3: Teste de Causalidade entre os preços da carne no atacado na Grande São Paulo e do boi gordo em Araçatuba. 48

Tabela 4: Teste de Causalidade entre os preços da carne no atacado na Grande São Paulo e do boi gordo em Bauru/ Marília. .49

Tabela 5: Teste de Causalidade entre os preços da carne no atacado na Grande São Paulo e do boi gordo em Presidente Prudente. .50

Tabela 6: Teste de Causalidade entre os preços da carne no atacado na Grande São Paulo e do boi gordo em São José do Rio Preto. 52

Tabela 7: Teste de Causalidade entre os preços da carne no atacado na Grande São Paulo e o Indicador de Preços de Boi Gordo 53

Tabela 8: Teste de Causalidade entre os preços da carne no atacado na Grande São Paulo e do boi gordo em Tres Lagoas. 55

Tabela 9: Teste de Causalidade entre os preços da carne no atacado na Grande São Paulo e do boi gordo em Campo Grande. .57

Tabela 10: Teste de Causalidade entre os preços da carne no atacado na Grande São Paulo e do boi gordo em Goiás.

Tabela 11: Teste de Causalidade entre os preços da carne no atacado na Grande São Paulo e do boi gordo no Triângulo Mineiro. 
Tabela 12: Teste de Causalidade entre o Indicador de Preços de boi e os preços de boi gordo em Tres Lagoas.

Tabela 13: Teste de Causalidade entre o Indicador de Preços de boi e os preços de boi gordo em Campo Grande. 64

Tabela 14: Teste de Causalidade entre o Indicador de Preços de Boi e os preços de boi gordo no Triângulo Mineiro.

Tabela 15: Teste de Causalidade entre o Indicador de Preços de Boi e os preços de boi gordo no estado de Goiás. 66

Tabela 16: Resultados dos modelos com melhor ajuste do Teste de Causalidade entre os preços da carne na Grande São Paulo e os preços de boi no estado. .67

Tabela 17: Resultados dos modelos com melhor ajuste do Teste de Causalidade entre os preços de boi no estado de São Paulo e os preços da carne na Grande São Paulo. 69

Tabela 18: Resultados dos modelos com melhor ajuste do Teste de Causalidade entre os preços da carne na grande São Paulo e os preços de boi fora do estado de São Paulo 70

Tabela 19: Resultados dos modelos com melhor ajuste do Teste de Causalidade entre os preços de boi fora do estado de São Paulo e os preços da carne na grande São Paulo. .71

Tabela 20: Resultados dos modelos de melhor ajuste para os testes de causalidade entre o Indicador de Preços do boi gordo e os preços de boi gordo fora do estado de São Paulo. .72

Tabela 21: Resultados dos modelos de melhor ajuste para os teste de causalidade entre os preços de boi gordo fora do estado de São Paulo e o Indicador de Preços do boi gordo 


\section{INTEGRAÇÃO ENTRE OS MERCADOS DE BOI GORDO E DE CARNE BOVINA NO CENTRO- OESTE E SUDESTE DO BRASIL}

Autor: Sergio De Zen

Orientador: Geraldo Sant'Ana de Camargo Barros

\section{Resumo}

Este estudo visa detectar as relações que existentes entre os preços diários de boi gordo nas diversas regiões do centro-sul do Brasil e entre esses preços e o da carne bovina na região da Grande São Paulo. Mais especificamente, pretende-se verificar a existência de integração entre as diversas praças produtoras e entre os diferentes níveis de mercado. Esse estudo permite apontar níveis e locais que podem ser considerados lideres ou liderados no processo de formação de preço.

Foram ajustados vários modelos para se detectar a existência de causalidade entre as séries de preços diários do boi gordo nas regiões de Araçatuba, Presidente Prudente, São José do Rio Preto e Bauru /Marilia no estado de São Paulo, do Triângulo Mineiro, de Três Lagoas e Campo Grande no Mato Grosso do Sul e de Goías. Além da carne ao nível de atacado na região da Grande São Paulo. $O$ ajustamento dos modelos fica dificultado pela existência de autocorrelação nos resíduos, constatadas através do 
teste de Q. Esse problema foi eliminado mediante a utilização de filtros de CochraneOrcutt. Outro problema enfrentado no ajuste dos modelos é a determinação do número de defasagens a ser adotada, para tanto foram analisados a significância dos coeficientes das autocorrelações parciais .

Foram ajustados 16 modelos para as relações entre a carne e os preços de boi gordo em regiões do estado de São Paulo e o indicador, mais 15 modelos para o preço da carne e os preços de boi nas regiões circunvizinhas e 15 para o indicador de Preços do Boi Gordo ESALQ/BM\&F e os preços de boi fora do estado de São Paulo.

Os resultados evidenciaram um mercado altamente integrado, com respostas rápidas para alterações de preços em cada uma das regiões. Indicam também que não existem líderes no mercado. Alterações de preços podem ser causadas por fatores da próprio de cada região e transmitidas para outras. 


\section{INTEGRATION AMONG FED CATTLE AND BEEF MARKETS IN THE WEST- CENTER AND SOUTH-EAST REGION OF BRAZIL}

Author: Sérgio De Zen

Adviser: Geraldo Sant'Ana de Camargo Barros

\section{Summary}

This study seeks to detect and measure the relationships among fed cattle prices in different markets of Brazilian south-center region and among these prices and beef prices in the city of São Paulo. It is intended to verify the existence of price leadership by some of the markets.

To determine the relationships among prices, several models were adjusted to detect the existence of causality among the daily price series. Problens of residual correletions, detected by the $Q$ tests, were eliminated by the use of Cochrane-Orcutt filter. The choice of the number of lags to be used, was based on of Akaike and Schwarz tests. 
Sixteen models were adjusted for the relations among beef prices and fed cattle prices in different regions of São Paulo state. Fifteen models were used for beef and cattle prices in neighboring regions. Fifteen models were also a adjusted for ESALQ/BM\&F fed cattle price indicator and regional prices outside São Paulo state.

The results showed an highy integrated market, with quick responses to the price changes in individual regions. They also indicate that there is no market leadership. Price changes may be caused by anyown region own factors, and then transmitted to other regions. 


\section{Apresentação}

Este estudo pretende analisar o comportamento dos preços recebidos pelo produtor de boi gordo no estado de São Paulo e nas demais regiões que com ele interagem. O objetivo é verificar o grau de integração tanto entre as diversas praças formadoras de preço do boi como entre o nivel de produtor e o atacado em que se comercializam as carcaças dos animais. Com isso será possível aferir o nível de eficiência do mercado como um todo.

O estudo utiliza dados diários de preços nas diferentes praças e, dessa forma, reflete de forma intensa fatos econômicos e outros, ambos de curtíssimo prazo. Esses preços podem refletir efeitos de ocorrências climáticas de curta duração como, por exemplo, chuvas, geadas e veranicos. Também sofrem efeitos associados ao dia da semana, feriados, ou finais de semana prolongados. Os preços diários podem ainda ser influenciados pelo comportamento do mercado ao longo do mês. Assim, por exemplo, espera-se um aumento da demanda no início do mês, ocasião em que os assalariados concentram as suas compras. No final de mês, espera-se uma redução do consumo e uma elevação da oferta, quando os produtores têm maiores necessidades de fazer caixa. Trabalhar com preços diários é uma proposta inédita. Esses preços incorporam uma série de informações importantes, em geral ignoradas por analistas que trabalham com médias mensais ou semanais, mas fundamentais para agentes participantes do mercado. 
A pouca ênfase normalmente dada à análise de preços diários deve ser atribuída, antes de mais nada, à escassez de informações confiáveis desse tipo. Na verdade no Brasil, é relativamente recente a disponibilidade dessas informações, principalmente as produzidas por institutos/centros especializados e capacitados para tal fim. A atual disponibilidade de informações de mercado de alta freqüência deve-se em grande parte à possibilidade de utilização de meios de comunicação e de processamento de dados, que há pouco tempo tornaram-se acessiveis aos centros de pesquisa, incrementando sua agilidade.

Deve ser enfatizada inicialmente a relevância da análise de dados diários de preços, principalmente para os participantes do mercado físico, atentos ao mercado futuro. Tais agentes, que tomam decisões continuamente, alterando suas posições no mercado, têm demonstrado substancial interesse na divulgação dessas informações. Esse interesse decorre do fato de que esses dados - divulgados diariamente ou até várias vezes ao dia - ampliam o universo de informações para a tomada de decisão na medida que se tornam disponiveis a tempo de serem úteis nas transações de compra e venda. O fato de que esses dados diários utilizados sirvam também para a liquidação financeira de contratos futuros, amplia seu interesse por parte dos agentes de mercado.

A interpretação correta dos fatores ligados ao comportamento dos preços diários do boi e da sua carcaça depende de uma adequada compreensão dos processos de produção e comercialização desses produtos, analisados a seguir. 


\section{Aspectos Gerais da Produção e da Comercialização na Pecuária de Corte}

A análise a ser feita neste trabalho refere-se basicamente à macro-região composta pelo estado de São Paulo e regiões situadas no centro-oeste do Brasil, que são: Tres Lagoas e Campo Grande no estado de Mato Grosso do Sul, o Triangulo Mineiro e o estado de Goiás.

Tanto as unidades de produção como as de abate de animais acham-se dispersas por todo o território nacional. Entretanto, há uma concentração de ambas na região centro-sul (cerca de $76 \%$ do total, segundo os dados do IBGE, 1991). O principal mercado consumidor é o estado de São Paulo, que, apesar de possuir um rebanho menor que o dos outros estados da região, possui o maior parque de estabelecimentos de abate.

Nas últimas décadas, verifica-se deslocamentos de frigoríficos no sentido de se posicionarem mais próximos das áreas de maior produção. Com isso, a importância relativa do estado de São Paulo, em termos de capacidade de abate, vem sendo reduzida. 


\subsection{Formação de Preços}

A determinação dos preços internos de boi de cada região depende das condições ligadas à oferta e a demanda de animais para abate. Trata-se de um mercado que opera em condições de concorrência (MILLER,1987). A oferta de animais está relacionada à presença de outras atividades agrícolas, que podem oferecer rentabilidade alternativa ao produtor. A evolução da oferta depende da produção de alimentos para os animais, que, por sua vez, depende do manejo da pastagem e dos animais. As pastagens no Brasil passaram por um longo processo evolutivo. A disponibilidade de terras facilitou a expansão da pecuária de corte via aumento do rebanho e deslocamento da produção. A preocupação com relação ao aumento da produtividade veio somente nas últimas décadas com a valorização da terra e as dificuldades de abertura de novas áreas.

A demanda por animais deriva-se, em última instância, da demanda por carne pelo consumidor, que para ser atendida necessita de uma estrutura adequada de processamento e comercialização. Nesse sentido os produtores vizinhos a um frigorífico podem receber um preço melhor pelos seus animais, pois a indústria está deixando de gastar com o transporte dos animais. Portanto, os frigoríficos tendem a se fixar em regiões onde a oferta de animais é maior, pois os custos de se transportar um animal vivo é maior do que o de se transportar as carcaças. 


\subsubsection{Localização dos Frigoríficos}

Nos últimos 20 anos, as empresas ligadas ao setor de carne iniciaram um processo de deslocamento do abate em direção às regiões de produção. Por exemplo, início da década de 70 existiam 5 unidades de abate cadastradas no Serviço de Inspeção Federal -SIF localizadas na região da Grande São Paulo. Em 1995, praticamente todas as unidades de abate dessa região estavam desativadas. Com relação ao parque industrial de abate paulista, é interessante notar também que as empresas cadastradas no SIF passaram de 22 para 76, no período de 1963 a 1995.

Atualmente a região da Grande São Paulo se notabiliza por concentrar muitos estabelecimentos de desossa e distribuição de carne. Nos registros do SIF de 1994, existem 79 empresas cadastradas como aptas a fazer desossa no estado de São Paulo, das quais apenas 11 estão fora da Grande São Paulo. Existem ainda 19 empresas cadastradas como entrepostos de carne.

A capacidade de abate das unidades da federação evoluiu no sentido de acompanhar a produção. O estado de São Paulo que em 1970 era responsável por $34,5 \%$ do abate, viu sua participação cair até o nivel de 23\% em 1990. Em 1994 o estado foi responsável por $26 \%$ do abate. No mesmo período, o Mato Grosso do Sul foi o estado 
que apresentou maior crescimento. Em 1979, quando o estado foi desmembrado de Mato Grosso, participava com 5,16\%, em 1994 sua a participação súbiu para $17,96 \%$.

A figura 1 mostra que também perdem importância estados como o Rio Grande do Sul e Minas Gerais, enquanto Goiás e Mato Grosso do Sul aumentam a participação. A Figura 1 apresenta a evolução do abate de acordo com os dados do SIF ilustra a evolução do setor.

\section{Abate de Bovinos}

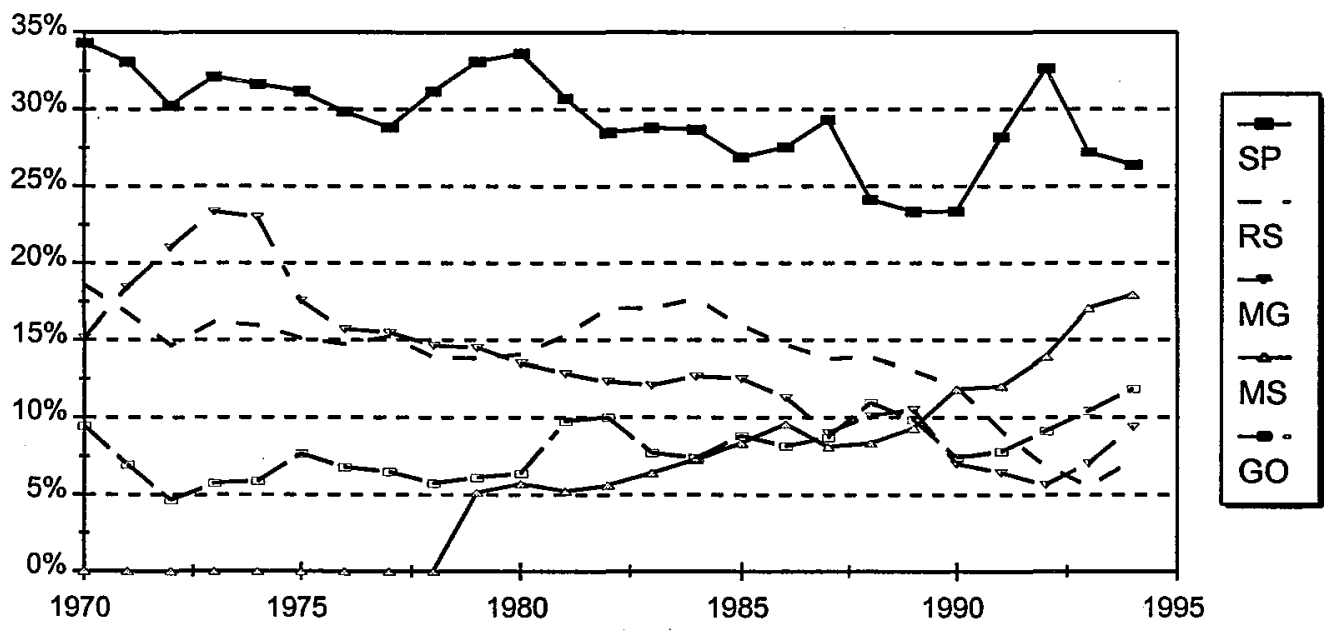

Fonte:SIF

Figura 1 : Volume de bovinos abatidos pelos frigoríficos nas príncipais regiões produtoras 


\subsubsection{Transporte}

Os preços dos animais e das carnes nas diferentes regiões são interligadas pelos custos de transporte de ambos.

O transporte dos animais vivos para o abate através de longas distâncias pode inviabilizar muitas empresas. A tabela 1 apresenta o custo do transporte do boi gordo nos estados de São Paulo, Mato Grosso do Sul, Goiás, Paraná e Minas Gerais. Os valores como pode ser observado são bastante próximos.

Tabela 1 - Cotações por Quilometro para Transportar Animais Vivos

\begin{tabular}{l|l}
\hline \multicolumn{1}{c|}{ Região } & Valor $R \$ / \mathrm{km}^{*}$ \\
\hline São Paulo & 0,36 a 0,40 \\
Mato Grosso do Sul & 0,38 a 0,40 \\
Minas Gerais & 0,40 a 0,42 \\
Goiás & 0,42 \\
Paraná & 0,36 a 0,38 \\
\hline
\end{tabular}

Fonte: CEPEA

*Valores em reais de maio de 1996.

Os custos coletados confirmam o conhecimento popular, segundo a qual custo por quilômetro rodado é igual ao valor de um litro de óleo diesel. Os custos referem-se a uma 
carga média de 18 bois, mas, em alguns casos, essa carga pode chegar a 20 cabeças. O peso padrão considerado para cada animal gira em torno de 17 arrobas.

A localização dos frigoríficos tornou-se inadequada ao longo do tempo, principalmente após a ocupação de vastas áreas do estado de São Paulo com culturas como a cana-de-açúcar e a laranja. As áreas de pastagens do estado foram reduzidas e as empresas tiveram que passar a comprar os animais fora do estado.

De acordo com o relato de empresas que adquirem a carne como matéria-prima principal, os frigoríficos situados em regiões mais afastadas dos centros urbanos (regiões de consumo), como, por exemplo, a região Centro-Oeste do país, estão em melhores condições de concorrer, pois existe nessas regiōes maior oferta de animais e, portanto, os preços da arroba são menores. Por outro lado, o custo de transporte da carne é mais baixo do que o custo de transporte dos animais vivos, então, a tendência de transporte de carne desossada pode acentuar as vantagens dos frigoríficos localizados nas proximidades das regiões de produção. 


\subsubsection{Tributação}

Entre um nível de mercado e outro (produtor e atacado/indústria) e entre uma região e outra, a carga incidente de tributos explica boa parte dos diferenciais de preço.

O sistema de arrecadação é definido pelo estado para cada produto. No estado de São Paulo, por exemplo, o recolhimento do ICMS para o boi é antecipado, ou seja, o estado fixa um valor de pauta, sobre o qual incide uma alíquota que deve ser recolhida antes do animal ser embarcado. Isto é feito através de uma guia retirada no posto fiscal da receita estadual, sendo o imposto recolhido num banco comercial (Regulamento do ICMS de SP).

No estado de Mato Grosso do Sul, por outro lado, o pagamento do imposto é feito após quinze dias o abate, quando este se dá no próprio estado. Para os animais que vão ser abatidos em outros estados, o imposto deve ser recolhido antes do embarque dos animais. Desta forma, as empresas estabelecidas no estado ficam favorecidas.

O estado do Paraná adota uma política semelhante a do Mato Grosso do Sul, ou seja, o recolhimento é feito após o abate. O estado de Minas Gerais tem legislação parecida com a paulista, sendo o imposto recolhido antecipadamente. 
O valor de pauta também é variável considerando os diversos estados. Este valor tem por finalidade fixar uma base para o recolhimento. Por exemplo, o estado fixa um valor de $R \$ 430,00$ para a pauta, de forma que serão recolhidos $12 \%$ sobre este valor, ou seja, $R \$ 51,60$, não importando se este animal pesa 18 ou 16 ou 15 arrobas. Logo, para o contribuinte é interessante abater o animal mais pesado.

A pauta é importante para o estado fazer alterações efetivas da alíquota, evitando a necessidade de aprovação por unanimidade pelo CONFAZ e a regulamentação pelo senado. A estratégia adotada é, então, alterar a base de cálculo. Exemplo disto é a redução da base de 41,72 \% dada pelo estado de São Paulo. Assim a alíquota de $12 \%$, na realidade passa a corresponder a $7 \%$ (LíCIO,1994).

O ICMS apresenta três grupos de alíquotas. Tomando como exemplo o estado de Minas Gerais, apresenta-se a seguinte divisão. Para transações entre os estados do sul e sudeste, menos o estado do Espírito Santo, aplica-se uma alíquota entre 0 e $12 \%$. Para transações interestaduais com as demais regiões a alíquota é de 0 a $13 \%$ para exportações, e para transações dentro da região, a alíquota varia de 0 a $25 \%$.

Ao atacado é importante observar se o crédito foi calculado sobre a alíquota de 7 ou de $12 \%$. No caso da carne com origem no estado de Mato Grosso do Sul, este crédito é calculado com base em $12 \%$, mesmo que ocorram as devoluções de 4,6 ou $8 \%$ que são previstas na legislação de insentivo ao abate de novilho precoce no estado de Matogrosso do Sul. Isto significa que, se um determinado frigorifico comprou seus bois e pagou 100 unidades monetárias - u.m., vai recolher 12 u.m. caso este animal esteja 
incluído dentro de uma categoria de "novilho precoce", e tendo direito a devolução de $6 \%$. O recolhimento líquido será de 6 u.m.. No entanto, quando da venda da carne, este frigorífico terá um crédito sobre o imposto de 12 u.m.. Logo se o valor a ser recolhido, nesta etapa da comercialização, for de 20 u.m., o recolhimento efetivo será de 8 u.m.. A arrecadação total em Mato Grosso do Sul será, portanto, de 14 u.m..

No caso do frigorifico paulista, para a mesma transação, a arrecadação inicial é de 7 u.m. e o crédito a ser descontado no momento da venda da carne é de 7 u.m.. Então se o valor a ser recolhido na venda da carne é 20 u.m. o valor recolhido efetivamente nesta etapa será de 13 u.m.. A arrecadação total em São Paulo será, portanto, de 20 u.m. .

\subsection{Relações Comerciais}

Os negócios entre os pecuaristas e os frigoríficos são feitos em praticamente todos os casos através de corretores. São agentes que fazem a compra para os frigoríficos, atuando de várias formas: a) podem ser funcionários do frigorifico e, desta forma, fazer a compra dentro da própria empresa; b) autônomos, que trabalham em escritórios dentro da empresa, recebendo uma comissão sobre o valor da compra; c) autônomos que mantêm escritórios fora do frigorifico, mas são compradores exclusivos de uma empresa, trabalhando por comissão; d) autônomos, mantendo um escritório especializado em compras de animais, mas trabalham para vários frigorificos ao mesmo tempo, recebendo por comissão ou trabalhando com um "spread", ou seja, compram por 
um determinado preço e repassam ao frigorífico por um preço com algum acréscimo e/ou com prazos diferenciados.

A figura desse intermediário ganha força principalmente em razão da desorganização e da falta de transparência com que alguns frigoríficos operam. $O$ principal ponto de desacordo entre as partes é com relação ao rendimento de carcaça. Então, o corretor oferece o serviço de "acompanhamento da matança", que nada mais é do que fiscalizar o trabalho de limpeza das carcaças.

A transação é feita geralmente obedecendo a uma escala para o abate dos animais, que gira em torno de 3 dias, entre a venda e o abate. Prazo de pagamento entre 10 e 30 dias é o mais usual.

As negociações descritas acima são feitas em praticamente todos os dias úteis do ano, havendo maior freqüência de negócios na época da safra do boi, que compreende os meses de abril a junho. O fato de haver negociação todos os dias faz com que os preços da arroba seja influenciados por fatos, inclusive conjunturais, de efeitos momentâneos ou seja que são dissipados rapidamente. Como exemplos desses fatos podem ser mencionados os seguintes: dias de chuva, o dia dos pagamento de salários e os feriados com finais de semanas prolongados.

Um período de vários dias de chuva afeta o preço de duas maneiras. Por um lado, dificulta a saída dos animais das fazendas, com isso os frigoríficos tendem a ofertar um 
preço melhor por animais cuja facilidade do transporte seja maior. Por outro, pode prejudicar as saídas de carne do frigorífico para os centros consumidores e, com isso, compromete a oferta de carne, o que faz com que os preços pagos pela carne no atacado se elevam. Isto não significa que o mercado está alterando o nível de preços, mas apenas reagindo a uma circunstância momentânea.

Normalmente espera-se que a demanda por carne, e consequentemente seu preço seja maior, no início do mês uma vez que o pagamento dos salários geralmente ocorre, por força de lei, até o quinto dia útil do mês. Nos tempos de inflação elevada, o assalariado tinha bons motivos para apressar as suas compras; com a maior estabilidade dos preços, esse efeito pode ter se atenuado.

Nos feriados prolongados, ocorre um êxodo de significativa parcela da população dos grandes centros urbanos, em especial na cidade de São Paulo. Com isso, a comercialização de carne é reduzida nos dias que antecedem o feriado. Os frigoríficos, reduzem os abates e o preço da arroba de boi tende a sofrer queda por alguns dias. Passado o feriado o efeito desaparece.

Nos três casos citados, espera-se que o preço da arroba de boi retorne ao nível anterior, sem alterações significativas nas médias de preços praticadas no mês. 


\section{Objetivo e Hipótese}

\subsection{Objetivo}

O trabalho visa detectar as relações existentes entre os preços de boi gordo nas diversas praças do estado de São Paulo e regiões do Triangulo Mineiro, Goiás e do Mato Grosso do Sul, bem como os preços do boi e da carne bovina ao atacado.

\subsection{Hipóteses Básicas}

A hipótese básica do trabalho é a de que as diversas praças comercializadoras de boi e de carne devem operar integradamente do ponto de vista espacial. Resulta daí que as séries de preços observadas nessas praças devem apresentar fortes relações, que podem ser captadas estatisticamente. Ainda mais, é de supor que certas praças exerçam papel de liderança, no sentido de que se antecipam às demais por ocasião das alterações de preço. Ou seja, as demais praças desempenham papel mais passivo, seguindo uma estratégia de acompanhar as líderes por ocasião de mudanças de preços. A literatura tem 
sugerido que as praças com maiores volumes negociados, por disporem de mais informações, tendem a exercer o papel de líderes regionais no mercado (BARROS,1990).

Serão realizados testes de causalidade que para verificar se os movimentos de uma série de preços são causados pelos movimentos de outra série de preços. Testar causalidade significa, então, testar se os movimentos de uma série de preços $X$ precedem ao movimentos de uma série $Z$, ou se os movimentos da série $Z$ precedem aos movimentos da série $X$, ou ainda, se os movimentos das séres $X$ e $Z$ são simultâneos. 


\section{Metodologia}

\subsection{Fundamentos Teóricos}

Este trabalho pretende analisar as relações entre os preços de diferentes praças ou regiões. A teoria econômica estabelece hipótese sobre tais relações, onde tem papel fundamental o custo de transporte entre as regiões envolvidas. Os conceitos relevantes estão apresentados a seguir.

Considera-se inicialmente duas regiões, $\mathrm{X}$ e $\mathrm{Y}$, separadas espacialmente e entre as quais não ocorre transferência de produtos. Os preços regionais serão determinados pelas respectivas curvas de oferta e demanda, sendo $P_{x} \circ$ preço na região $X$ e $P_{y} \circ$ preço na região $Y$. Se $P_{x}>P_{y}$, e desconsiderando-se os custos de transferência, esperase que venha a ocorrer a transferência de produtos da região de menor preço para a de maior preço até que ocorra a igualdade de preços $\left(P_{x}=P_{y}\right)$. É o mecanismo conhecido como arbitragem em comércio regional.

Na figura 2 está ilustrado o comportamento que se espera dos mercados nessas condições. Com o fluxo de produtos da região $Y$ para a região $X$, espera-se que ocorra uma nova situação de equilibrio conjunto. Nesta figura procede-se a somatória das curvas 
de oferta e demanda das duas regiões. Como resultado dessas somas resultam novas curvas de oferta e de demanda, válidas para as duas regiões consideradas. No gráfico a quantidade de produto transferida é representada pelo segmento $a b=c d$. Com isso há um aumento do suprimento de produto na região $X, e$, consequentemente, um redução de $P_{x}$. Com a transferência de parte da produção de $Y$ para $X$, ocorre uma elevação de $P_{y}$.

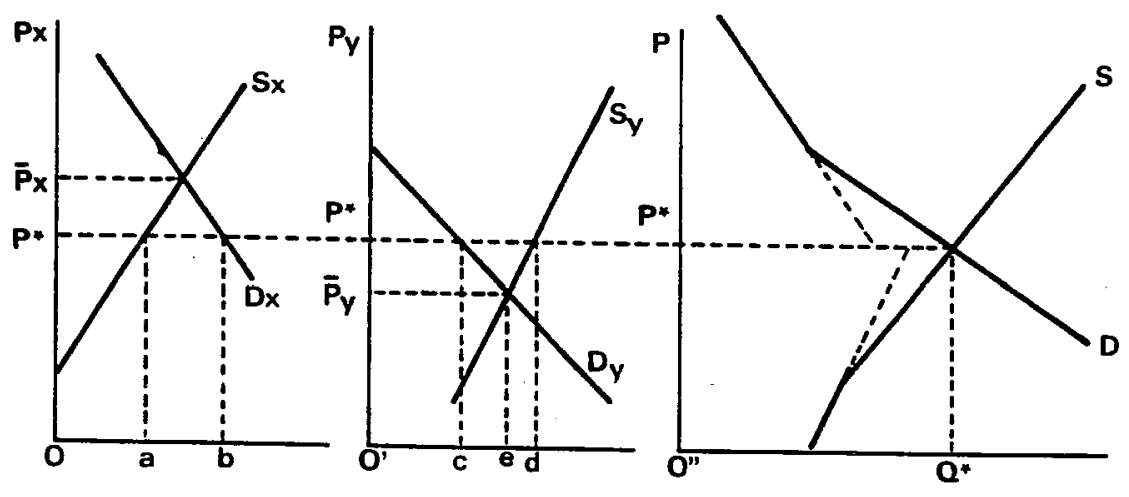

FIGURA 2 : COMÉRCIO REGIONAL SEM RECURSOS DE TRANSFERÊNCIA. (FONTE: BRESSLER \& KING, P.87, IN: BARROS, 1987, P 99) (FIGURA 4.1)

No caso em que o transporte implica custos, a condição básica para que ocorra comércio entre as regiões é que esse custo de transferência (CT) seja menor ou igual a diferença dos preços, ou seja, $P_{x}-P_{y} \geq C T$. Com a transferência de produto da região de 
menor preço para a região de preços mais elevados espera-se uma redução da produção nessa última região.

Uma maneira de analisar o efeito do custo de transferência sobre o comércio interregional é através do diagrama "back to back", apresentado na figura 3. O procedimento inicial é a obtenção da curva dos excessos de oferta de cada região (ES $\mathrm{x}_{\mathrm{X}}$ e ESY). A abcissa dessa curva corresponde a diferença horizontal entre as duas funções anteriores (oferta e demanda). A curva de excesso de oferta mostra o excedente (ou déficit) para cada nível de preço regional. A seguir, obtém-se a curva de diferença de excesso de oferta $\left(E S_{X}-E S_{Y}\right)$ que é a diferença vertical entre $E S_{X}$ e $E S_{Y}$ Ela mostra as diferenças de preço entre as regiões $\mathrm{X}$ e $\mathrm{Y}$ que seriam observadas para cada volume comercializado. Como a condição para que ocorra comércio inter-regional é que $\quad P x-P y \geq C T$, devese comparar as diferenças de preços (ordenada de ESx-ESy) com CT. Graficamente marca-se no diagrama uma linha horizontal de ordenada igual a CT (Og na figura 2 ). No ponto em que esta reta corta a curva ( ESx-ESy) ter-se-á o ponto em que Px $-\mathrm{Py}=\mathrm{CT}$ (ponto U), cuja abcissa dará a quantidade comercializada de $Y$ para $X$, ou seja, Oh.

$\mathrm{Na}$ figura 2, observa-se ainda que, se $\mathrm{CT}=0$, a quantidade transacionada seria $\mathrm{Of}$, onde (ESx-ESy) cruza o eixo horizontal. Com CT $=0 \mathrm{~g}$ a quantidade transportada será Oh. Outras informações importantes são os preços regionais. Para tal projeta-se para cima o ponto h sobre as curvas ESx e ESy. Px* será a ordenada do ponto sobre ESx e $\mathrm{Py}^{\star}$ a ordenada do ponto sobre ESy. 


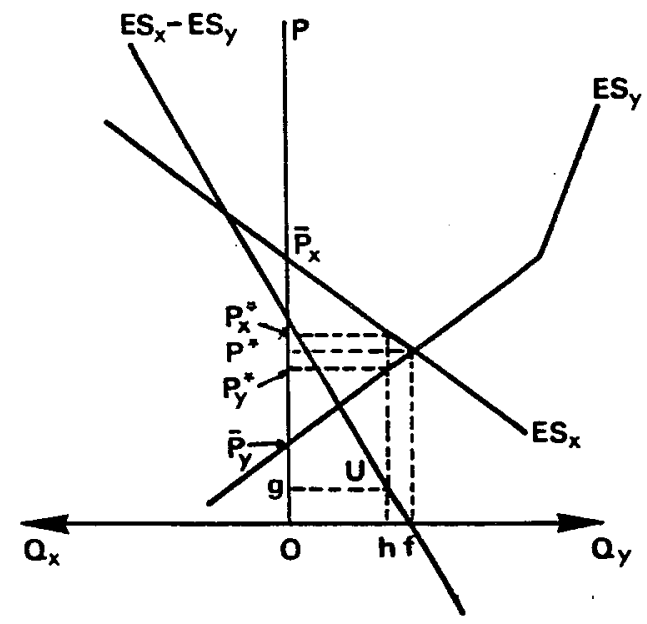

FIGURA 3: EFEITO DO CUSTO DE TRANSFERENNCIA SOBRE O COMÉRCIO (FONTE: BRESSLER \& KING, P. 91 IN: BARROS, 1987. P. 103) (FIGURA 4.4)

\subsection{Modelos multi-regionais de Comércio}

No caso mais geral, em que se considera várias regiões de produção e consumo, a análise do comércio pode ser feita pelo chamado modelo de transporte que tem a 
finalidade de obter as melhores rotas para o deslocamento dos produtos, de maneira a atender a demanda entre as regiões com o menor custo total de transporte. Num sistema competitivo essas seriam as rotas escolhidas para distribuição da produção.

O modelo parte das hipóteses de que um produto homogêneo é produzido em quantidades predeterminadas em $m$ pontos produtores e consumido em $n$ pontos consumidores. Os vários pontos de produção e de consumo são interligados por vias de transporte cujos custos são previamente conhecidos.

As regiões de produção são representadas pelas linhas de (1 a m)e as regiões de consumo são representadas pelas colunas de $(1$ a $n)$ As produções totais de cada região são representadas por $S_{\mathfrak{k}}$, apresentadas na última coluna, e a quantidades demandadas totais são representadas por $D_{j}$, apresentadas na última linha.

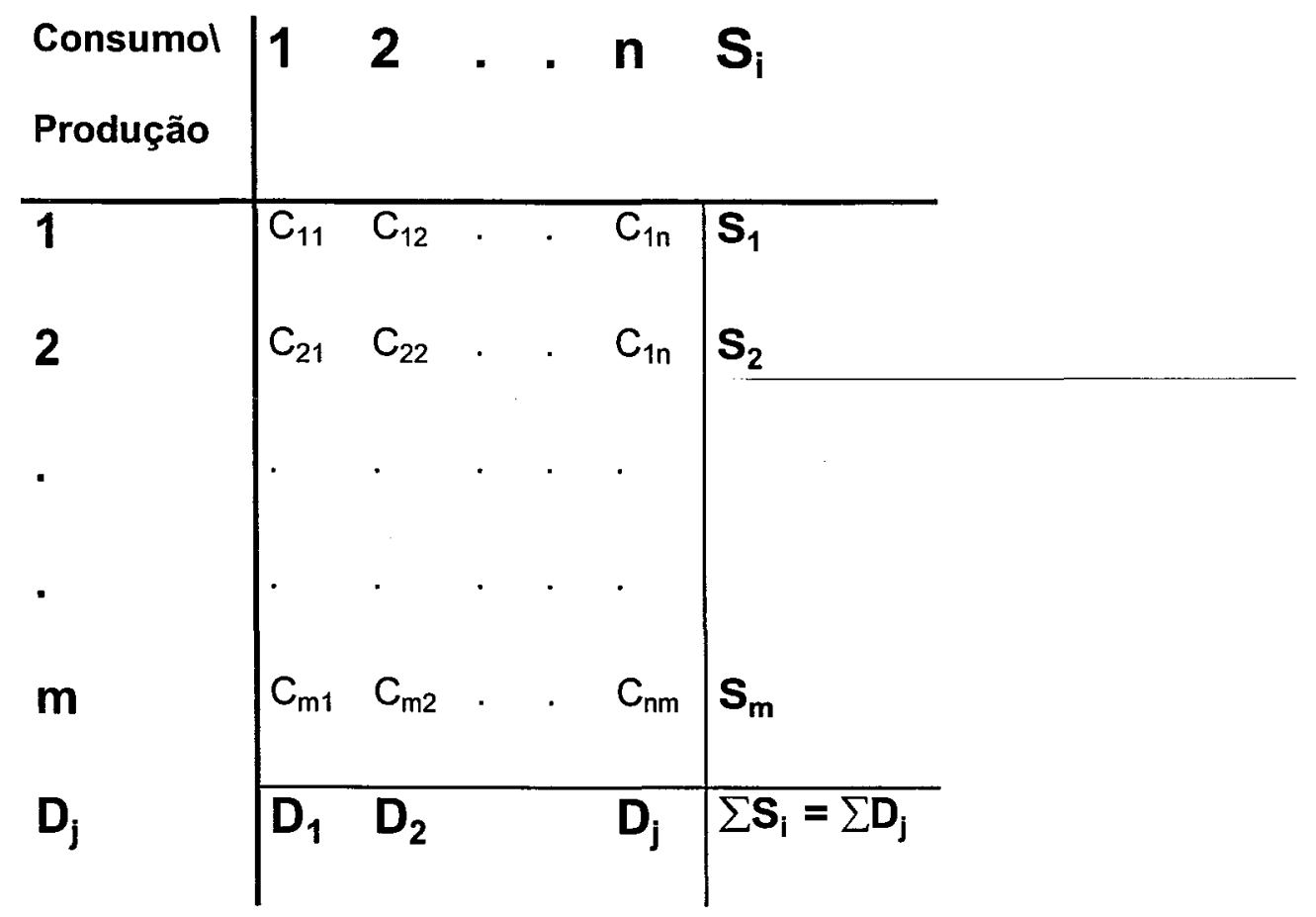


FIGURA 4: INFORMAÇÕES BÁSICAS PARA MODELOS MULTI-REGIONAIS

Considera-se $\mathrm{X}_{\mathrm{ij}}$ como sendo a quantidade de produto que é transferida da região de produção i para a região de consumo j, ao custo de transferência $C_{i j}$.

O custo total de transporte é dado pela somatória do custo de transporte multiplicados pelas correspondentes quantidades transportadas:

$$
C=\sum_{i} \sum_{j} X_{i j} C_{i j}
$$

O modelo deve obedecer a certas restrições como: a quantidade transferida deve ser igual ou menor do que a quantidade produzida na região de origem, e a quantidade transferida deve atender a demanda, portanto, deve ser igual ou maior a quantidade demandada.

A solução do problema permite escolher $(m+n-1)$ rotas ligando produção $e$ destino. Quaisquer duas regiōes ligadas pelo comércio terão seus preços relacionados pelos custos de transporte. 


\subsection{Preços Locais e Limites de Mercados}

Considera-se para fins teóricos a superfície de custo de transferência como o padrão de custo de transferência formado a partir de um mercado circundado pontos dispersos de produção. Considerando uma área uniforme e plana, a superfície mencionada pode ser vista transversalmente na (figura 4 (a) e (b)) e projetada no plano ( figura $4\left(a^{\prime}\right)$ e $\left(b^{\prime}\right)$ ).

$\mathrm{Na}$ figura 5 (a) estão dispostos os pontos de produção e na figura 5 (a') estão representas as superfícies onde os CT são iguais. Cada região circular apresentada no gráfico tem custos de transporte iguais, e são chamadas de região de isocusto. Neste gráfico os custos de transferência elevam-se de maneira uniforme. Nesta figura $b$ e b' representam os custos de transportes não lineares, logo o conjunto de regiões dos círculos tende a afastar-se do centro de maneira diferenciada, não havendo proporção entre distância e custo de transporte.

Os limites de mercados referem-se aos pontos em que é indiferente a venda do produto num ou noutro mercado considerado. No caso do mercado do boi gordo, os custos de transporte influenciam os preços em dois estágios. No primeiro, tem-se o efeito do custo de transporte das carcaças aos centros consumidores sobre os preços que os frigoríficos podem pagar aos produtores. Sendo que os frigoríficos mais distantes tenderão a operar com preços menores. O segundo estágio refere-se ao impacto dos 
custos de transporte dos animais até os frigorificos, do que resulta um preço local (líquido de custo de transporte) para cada produtor. Em geral espera-se que o produtor escolha aquele frigorifico que the oferece o melhor preço local. Assim, cada frigorifico tende a receber animais de uma determinada área ao seu redor. Entre as áreas de dois frigorificos tende a existir pontos em que há indiferença em relação ao ponto de entrega.
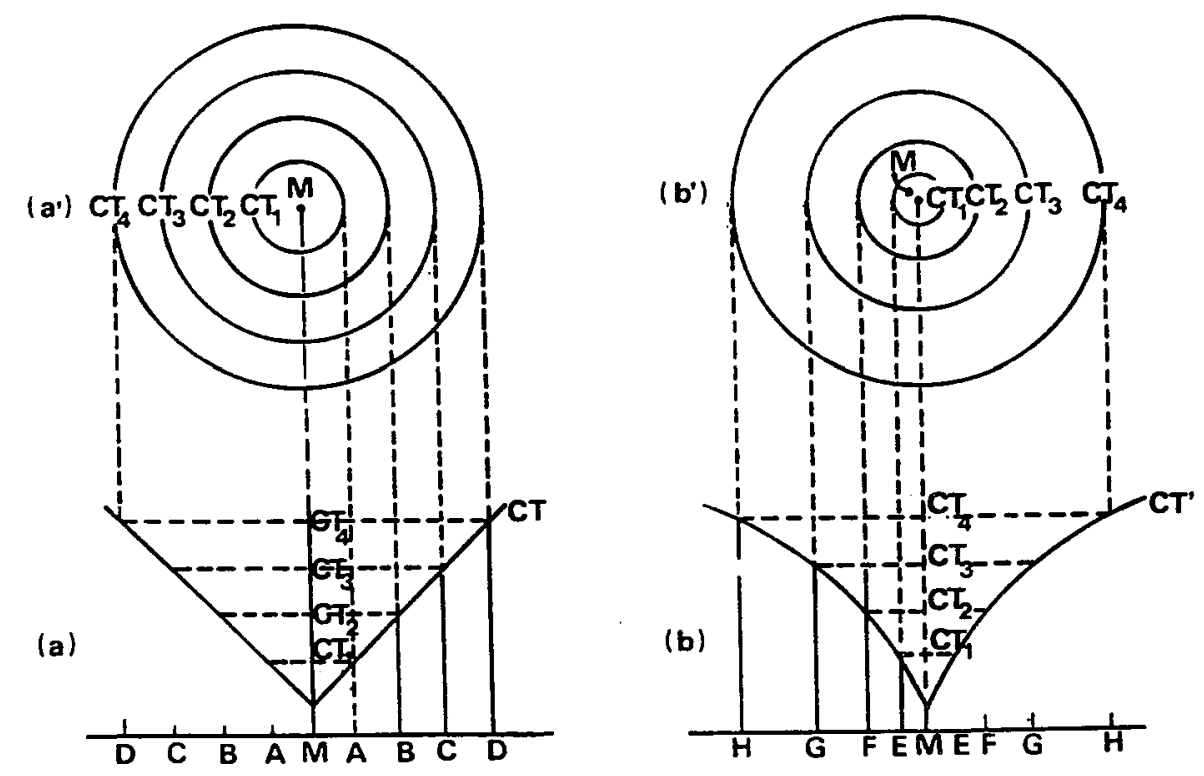

FIGURA 5: SUPERFICIES DE CUSTO DE TRANSFERENCIAS (FONTE: BRESSLER \& KING, P112. IN: BARROS, 1987. P 123. ( FIG. 4.9 )

Teoricamente o preço local - $P_{L}$ é dado pela diferença entre o preço no frigorífico$P_{m}$ e custo de transferência - CT, que, por sua vez, é uma função da distância (d) envolvida. O preço local pode ser representada pela seguinte fórmula: 
$P_{L}=P_{m}-C T=P_{m}-f(d)$

$\mathrm{Na}$ figura $6, \mathrm{P}_{\mathrm{A}}>\mathrm{P}_{\mathrm{B}}$ e sendo iguais as funções de custo de transferência, os pontos em que se cruzam as curvas de isopreço de mesmo nivel para os dois mercados se posicionam de modo a iniciar o envolvimento do mercado B (menor preço). A curva TUVXY indica isso. Essa curva é formada pelas projeções de pontos de preços locais iguais para os dois mercados. Ao longo da curva TUVXY esses preços diferem entre si e atingem o máximo no segmento $A B$.

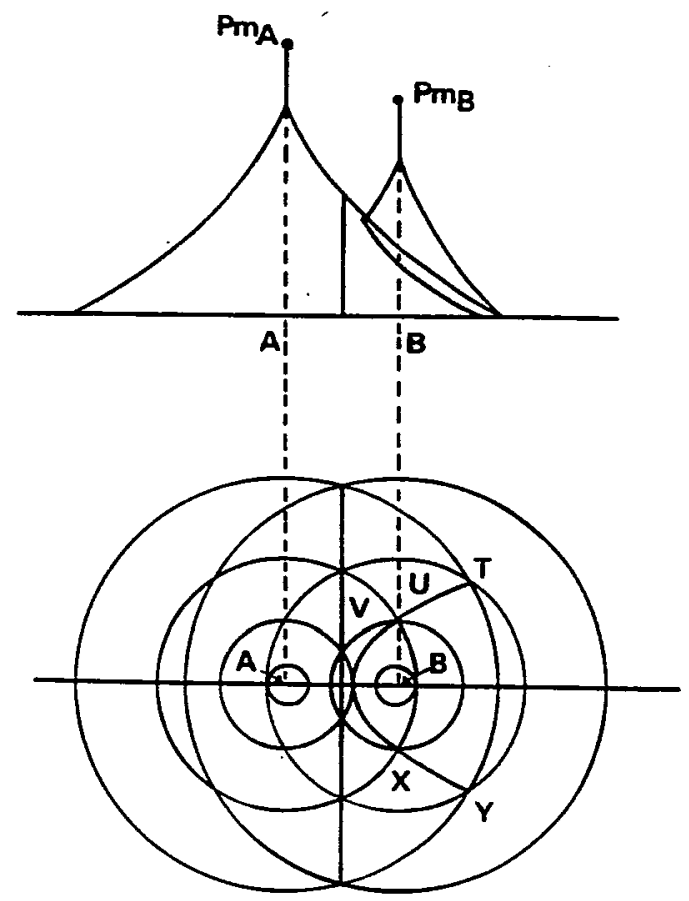

FIGURA 6: LIMITE ENTRE DUAS ÁREAS DE MERCADO COM PREÇOS DIFERENTES. (FONTE: BRESSLER \& KING, P. 128. IN: BARROS, 1987. P. 129) ( 4.12) 
$\mathrm{Na}$ figura 6, A e B podem ser interpretados tanto como dois mercados consumidores quanto como 2 frigoríficos. Assim essa figura serve para ilustrar tanto a determinação dos preços em diferentes frigoríficos em relação aos mercados consumidores $\mathrm{A}$ e $\mathrm{B}$, como a determinação dos preços locais recebidos pelos produtores tomando 2 frigoríficos A e B. Evidentemente, cada frigorifico escolhe o mercado consumidor the oferece maior preço pela carcaça. Do mesmo modo cada produtor escolhe o frigorífico que the rende o maior preço local.

Os pontos sobre o limite de mercado situam-se mais próximos de $B$, o mercado de menor preço, porque no referido limite, para ter preços locais iguais, $C T_{A}>C T_{B}$.

De acordo com a Lei das Áreas de Mercado (BRESSLER \& KING, pag 126- in BARROS,1987) o limite entre dois mercados ( $\mathrm{A}$ e $\mathrm{B}$ ) é dado pelo conjunto de pontos onde os preços locais, derivados dos dois mercados, são iguais, ou seja:

$P_{L A}=P_{L B}$

sendo que:

$P_{m A}-C T_{A}=P_{m B}-C T_{B}$

podendo esta fórmula ser escrita da seguinte maneira: 
$P_{m A}-P_{m B}=C T_{A}-C T_{B}$.

Ou seja, dados os preços em duas praças, por exemplo, o limite entre elas são locais cujos custos de transporte delas e relação ao mercado consumidor diferem por um valor constante igual à diferença de preços nas praças.

Deve-se observar uma relação forte entre o preço da carcaça na capital e os preços do boi praças consideradas:

$P_{c}=\left(P_{b_{1}}+C P_{i}\right)+C T_{i, M C}$

Onde:

$P_{c} \rightarrow$ preço da carcaça/ arroba em SP.

$P_{b_{i}} \rightarrow$ preço do boi no frigorífico i / arroba

$C P_{i} \rightarrow$ custo de processamento no frigorífico i /arroba

$C T_{i, M C} \rightarrow$ custo de transferência do frigorífico i para mercado consumidor (MC)/ arroba.

Ou alternativamente:

$P_{b i}=P_{C}-C P_{i}-C T_{i, M C}$ 
e também:

$$
P_{b j}=P_{c}-C P_{j}-C T_{j, M C}
$$

Logo

$$
P_{b i}-P_{b j}=\left(C P_{j}-C P_{i}\right)+\left(C T_{j, M C}-C T_{j, M C}\right)
$$

Se $C P_{j}-C P_{i}=0$, isto é, os 2 frigoríficos $i$ e $j$ tiverem os mesmos custos de processamento, então os preços das 2 praças diferem pela diferença entre os custos de transporte a São Paulo.

A análise teórica apresentada mostrou que os preços nas diversas regiões tende a estar fortemente relacionados face à arbitragem que deverá ocorrer entre elas. Essa arbitragem sugerirá que as diferenças de preços entre regiões deverá estar bastante próxima das diferenças de custo de transporte envolvido.

Por essa razão, as séries de preços para praças e níveis de mercado diferentes devem estar bastante próximos entre sí. Dessa forma, quando uma praça/região lider iniciar um alteração de preços surgirá margem para arbitragem lucrativa e se o mercado como um todo for suficientemente integrado, as discrepâncias de preços (além do transporte e tributos) deverão desaparecer com relativa rapidez. 


\subsection{Dados Básicos}

Para estudar as relações de preços da pecuária de corte foi necessário a definição de uma região de consumo de carne bovina e das regiões de produção. A região de consumo escolhida foi a grande São Paulo, pois trata-se do maior centro consumidor do país. Foram utilizados os dados de preços relativos às partes da carcaça de boi, levantados pelo Centro de Estudos Avançados em Economia Aplicada - CEPEA junto a escritórios de intermediação de carne. O cálculo do preço do boi no atacado foi feito a partir dos preços do traseiro, dianteiro e da ponta de agulha, ponderados de acordo com o sistema de ponderação descrito pelo Instituto de Tecnologia de Alimentos - ITAL (CANTO, 1986).

Os preços de animais prontos para o abate utilizados são relativos às seguintes praças: Araçatuba, Presidente Prudente, São José do Rio Preto e Bauru/Marília, no estado de São Paulo, das regiões de Três Lagoas e Campo Grande no Mato Grosso do Sul, do Triângulo Mineiro em Minas e do estado de Goiás. Esses preços também são levantados pelo CEPEA.

Os dados utilizados num total 487 observações correspondentes ao período de julho de 1997 a maio de 1996 são nominais e de periodicidade diária. 


\subsection{Métodos Econométricos}

\subsubsection{Teste de Causalidade ${ }^{1}$}

Com base nos conceitos de Granger (1969), Sims (1972) desenvolveu um teste de causalidade que consiste em estimar as seguintes equações:

$\operatorname{Pr}_{1}=\sum_{i=-k_{1}}^{k_{2}} \alpha_{i} \operatorname{Pr}_{2,(t-1)}+u_{t}$

$\operatorname{Pr}_{2}=\sum_{i=-k_{1}}^{k_{2}} \beta_{i} \operatorname{Pr}_{1,(t-i)}+v_{t}$

Onde :

$\operatorname{Pr}_{1} \rightarrow$ preço da arroba de boi na região 1.

$\mathrm{Pr}_{2} \rightarrow$ preço da arroba de boi na região 2 .

$\alpha_{i} \rightarrow$ parâmetros estimados para a equação 1.

$\beta_{i} \rightarrow$ parâmetros estimados para a equação 2 .

$\mathrm{u}_{t}$ e $\mathrm{v}_{t} \rightarrow$ erros aleatórios.

Ao se estimar as equações 1 e 2 para realizar o teste de causalidade, alguns cuidados devem ser tomados. Os principais deles são: a eliminação da autocorrelação

\footnotetext{
'Este tópico foi baseado em Aguiar,1990 e Bacchi 1994.
} 
entre os resíduos das regressões e a definição dos números de defasagens $\left(k_{2}\right)$ e valores futuros $\left(k_{1}\right)$ da variável explicativa que devem ser usados nas equações.

As hipóteses a serem testadas são as seguintes:

i) os coeficientes dos valores futuros da variável independente da equação 9 são zero.

ii) os coeficientes dos valores futuros da variável independente da equação 10 são zero.

Se as duas hipóteses forem rejeitadas ter-se-á relação bi-causal e se ambas não forem rejeitadas ter-se-á ausência de causalidade. Se a primeira hipótese for rejeitada e a segunda não, a causalidade será de $\mathrm{Pr}_{1}$ para $\mathrm{Pr}_{2}$, e, caso a primeira não seja rejeitada e a segunda seja, a causalidade será de $\mathrm{Pr}_{2}$ para $\mathrm{Pr}_{1}$.

As estimativas dessas equações requerem a realização prévia de filtragem das séries quando for detectada a autocorrelação dos residuos na regressão, indicada pelo teste de Durbin - Watson para correlação de $1^{\mathrm{a}}$ ordem e teste $\mathrm{Q}$ de Ljung - Box para grupos de correlações.

É importante detectar a presença de autocorrelação entre os residuos devido aos efeitos que essa pode causar no caso de se usar os estimadores convencionais dos parâmetros das equações (mínimos quadrados ordinários). A existência de correlação de residuo faz com que seja violada uma das pressuposições básicas para a utilização de análise de regressão. Quando as perturbações são auto-regressivas, as fórmulas convencionais para efetuar testes de significância ou construir intervalos de confiança 
com relação a coeficientes de regressão levam a resultados incorretos (ver KMENTA, 1988).

As filtragens das séries para a eliminação de autocorrelação residual podem ser feitas utilizando-se o filtro de Cochrane - Orcutt. Essa técnica de filtragem consiste no seguinte:

(a) Através de mínimos quadrados ordinários (MQO) obtém-se as estimativas de, por exemplo:

$\operatorname{Pr}_{1 t}=\sum_{i=-k_{1}}^{k_{2}} \alpha_{i} \operatorname{Pr}_{2,(t-i)}+u_{3 t}$

onde $\mathrm{Pr}_{1}$ e $\mathrm{Pr}_{2}$ são variáveis testadas.

(b) calculam-se os resíduos $u_{1}, u_{2}, \ldots, u_{n}$ e, a partir dai, $\rho$. No caso de autocorrelação de primeira ordem tem-se,

$$
\hat{\rho}=\frac{\sum \hat{u}_{t} \hat{u}_{t-1}}{\sum \hat{u}^{2}}
$$

(c) Constrói-se posteriormente novas variáveis:

$$
\operatorname{Pr}_{1 \mathrm{t}}^{*}=\left(\operatorname{Pr}_{1 t}-\hat{\rho} \operatorname{Pr}_{1,(\mathrm{t}-1)}\right) \quad \text { e } \quad \operatorname{Pr}_{2 t}^{*}=\left(\operatorname{Pr}_{2 t}-\hat{\rho} \operatorname{Pr}_{2,(t-1)}\right)
$$


e obtém-se a estimativa de:

$$
\operatorname{Pr}_{1 \mathrm{t}}^{*}=\sum_{i=-k_{1}}^{k_{2}} \alpha_{1} P^{*} r_{2,(t-i)}+\mu_{\mathrm{t}}
$$

Essa sistemática deve ser repetida recursivamente para as defasagens que apresentarem autocorrelação elevada nos residuos até que toda autocorrelação tenha sido removida. A eliminação da autocorrelação de período $n$ entre os erros é tida como completa quando o $\theta$ estimado na equação:

$$
\mu_{t}=\theta\left(\mu_{(t-n)}\right)+v_{t} \quad \mathrm{n}=1,2, \ldots, \mathrm{j}
$$

apresentar-se não significativo estatisticamente, considerando um nível de $5 \%$ de probabilidade pela utilização do teste " $\mathrm{t}$ " de Student.

A identificação das defasagens que apresentam autocorrelação elevada nos residuos pode ser feita através da análise das autocorrelações e autocorrelações parciais. Este assunto será discutido na próxima seção.

Sims (1972) comenta que o número de valores futuros e passados da variável explicativa deve ser suficientemente grande para permitir a captação do sentido de causalidade pelo teste, porém não tão elevado que venha causar problemas de multicolinearidade. O teste de causalidade nas séries desprovidas de correlação nos 
residuos (testa as hipóteses de serem nulos os coeficientes futuros da variável independente nas equações 1 e 2), é feito através da estatística de F. A estimação do valor de F é feita pela seguinte fórmula:

$$
F=\frac{\frac{\left(S_{\mathrm{r}}-\mathrm{SQR}_{\mathrm{u}}\right)}{(\mathrm{q}-\mathrm{p})}}{\frac{\mathrm{SQR}}{(n-q)}}
$$

Onde:

$S Q R_{r} \rightarrow$ soma dos quadrados dos resíduos da equação com restrição (sem valores futuros).

$\mathrm{SQR}_{\mathbf{u}} \rightarrow$ soma dos quadrados de resíduos da equação sem restrição (com valores futuros).

$q \rightarrow$ número de parâmetros estimados na equação sem restrição.

$\mathrm{p} \rightarrow$ número de parâmetros estimados na equação com restrição.

$\mathrm{n} \rightarrow \mathrm{n}^{\circ}$ de observações. 


\subsubsection{Autocorrelação e Autocorrelação Parcial ${ }^{2}$}

\subsubsection{Autocorrelação}

Os valores das autocorrelções praciais foram utilizados como indicativos da ordem de filtragem a serem realizadas com as séries de preços, afim de se eliminar as autocorrelações dos resíduos. Neste tópico estão apresentados o modelo teórico geral para o cálculo da autocorrelação parcial.

A autocovariância com defasagem $K$ de uma série temporal pode ser expressa por:

$\partial_{K}=E\left[\left(Z_{t}-u\right)\left(Z_{t+K}-u\right)\right]$

A variância é dada por:

$\partial_{0}=E\left[\left(Z_{t}-u\right)^{2}\right]$

A correlação com defasagem $K$ é então:

$\rho_{K}=\frac{\partial_{K}}{\partial_{0}}=\frac{E\left[\left(Z_{t}-u\right)\left(Z_{t+K}-u\right)\right]}{E\left[\left(Z_{t}-u\right)^{2}\right]}$

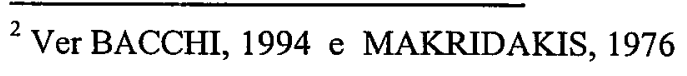


A estimativa de autocorrelação com defasagem $K$ é então:

$r_{K}=\frac{\sum_{t=K+1}^{n} \tilde{Z}_{t} \tilde{Z}_{t-K}}{\sum_{t=1}^{n} \tilde{Z}_{t}^{2}}$

com:

$\tilde{Z}_{t}=Z_{t}-\bar{Z}$

Para testar a significância da autocorrelação compara-se o seu valor com o desvio padrão da autocorrelação estimada, que é dado por:

$\hat{\sigma}\left(r_{K}\right)=\sqrt{\frac{1}{n}\left(1+2 \sum_{v=1}^{k-1} r_{v}^{2}\right)}$

$$
\text { Para } K=1 \text {, tem-se } \bar{\sigma}\left(r_{K}\right)=\sqrt{1 / n}
$$

com $n$ sendo o tamanho da amostra. 
$\mathrm{Na}$ prática considera-se $\mathrm{r}_{\mathrm{K}}$ como sendo significantemente diferente de zero se $\left|r_{K}\right|>t_{j} \hat{\sigma}\left(r_{K}\right)$ onde $t_{j}$ é o valor de estatística de "t" de Student com $\mathrm{n}-1$ graus de liberdade a 0,95 de probabilidade ( $\cong 2$ para $n$ grande $)$.

No caso de resíduos, $\left(\hat{a}_{\mathrm{t}}\right)$, a estimativa da autocorrelação com defasagem $\mathrm{K}$ é dada por:

$r_{K}=\frac{\sum_{t=K+1}^{n} \hat{a}_{t} \hat{a}_{t-K}}{\sum_{t=1}^{n} \hat{a}_{t}^{2}}$

\subsubsection{Autocorrelação Parcial}

Suponha-se os modelos:

$\tilde{Z}_{t}=\phi_{1} \tilde{Z}_{t-1}+a_{t}$

e

$\tilde{Z}_{t}=\phi_{1} \tilde{Z}_{t-1}+\phi_{2} \tilde{Z}_{t-2}+a_{t}$ 
que podem ser reescritos como:

$\tilde{Z}_{t}=\phi_{11} \tilde{Z}_{t-1}+a_{t}$

$\tilde{Z}_{t}=\phi_{21} \tilde{Z}_{t-1}+\phi_{22} \tilde{Z}_{t-2}+a_{t}$ (21 a)

Se o verdadeiro modelo for o primeiro e não o segundo então:

$\phi_{11} \quad$ em 20 (a) é diferente de zero e $\phi_{21}$ em 21 (a) é igual a zero.

Para a identificação do verdadeiro modelo deve-se, então, testar a significância dos coeficientes associados às defasagens de forma seqüencial. $\phi_{11}, \phi_{22}, \ldots, \phi_{K K}$.

A correlação parcial mede a correlação remanescente entre $Z_{t}$ e $Z_{t-j}$ depois de eliminada a influência das variáveis intermediárias $\tilde{Z}_{t-1}, \tilde{Z}_{t-2}, \ldots, \tilde{Z}_{t-(j-1)}$.

O processo para a obtenção da autocorrelação parcial consiste no seguinte:

Multiplicando-se (20 a ) por $\tilde{Z}_{t-1}$ e tomando-se a esperança matemática: 
$\delta_{1}=\phi_{11} \delta_{0}$

e dividindo-se por $\delta_{0}$ tem-se que:

$\rho_{1}=\phi_{11}$

Multiplicando-se (21 a ) por $\tilde{Z}_{t-1}$ e tomando-se a esperança matemática tem-se:

$\delta_{1}=\phi_{21} \delta_{0}+\phi_{22} \delta(-1)$

e como $\delta(-1)=\delta(1)$ pode-se escrever, depois de dividir a equação por $\delta_{0}$ :

$\rho_{1}=\phi_{21}+\phi_{22} \rho_{1}$

Multiplicando-se ( 21 a ) por $\tilde{Z}_{t-2}$ obtém-se:

$\delta_{2}=\phi_{21} \delta_{1}+\phi_{22} \delta_{0}$

e dividindo por $\delta_{0}$

$\rho_{2}=\phi_{21} \rho_{1}+\phi_{22}$

Tem-se então:

$$
\rho_{1}=\phi_{21}+\phi_{22} \rho_{1}
$$


$\rho_{2}=\phi_{21} \rho_{1}+\phi_{22}$

Esse sistema é chamado equações de Yule - Walker e pode ser escrito da seguinte forma matricial:

$\left[\begin{array}{cc}1 & \rho_{1} \\ \rho_{1} & 1\end{array}\right] \times\left[\begin{array}{l}\phi_{21} \\ \phi_{22}\end{array}\right]=\left[\begin{array}{l}\rho_{1} \\ \rho_{2}\end{array}\right]$

Tem -se então:

$\phi_{22}=\frac{\left|\begin{array}{cc}1 & \rho_{1} \\ \rho_{1} & \rho_{2}\end{array}\right|}{\left|\begin{array}{cc}1 & \rho_{1} \\ \rho_{2} & 1\end{array}\right|}=\frac{\rho_{2}-\rho_{1}^{2}}{1-\rho_{1}^{2}}$

A estimativa de autocorrelação parcial $\phi_{K K}$ é obtida substituindo as autocorrelações pelas suas estimativas.

Considera-se $\phi_{K K}$ diferente de zero se ela for maior que dois desvios padrão. Sendo o desvio padrão dado por $1 / \sqrt{n}$.

Para a generalização do conceito considera-se o seguinte modelo: 
$\tilde{Z}=\phi_{1} \tilde{Z}_{t-1}+\phi_{2} \tilde{Z}_{t-2}+\ldots+\phi_{p} \tilde{Z}_{t-p}+a_{t}$

Multiplicando-se (28) por $\tilde{Z}_{t-k}$ e aplicando-se esperança, obtém-se:

$\delta_{k}=\phi_{1} \delta_{k-1}+\phi_{2} \delta_{k-2}+\ldots+\phi_{p} \delta_{k-p} \quad k>0$

sendo:

$E\left(\tilde{z}_{t-k} a_{t}\right)=0 \quad$ para $\mathrm{k}>0$

Dividindo-se (29) por $\delta_{0}$ resulta em:

$\rho=\phi_{1} \rho_{k-1}+\phi_{2} \rho_{k-2}+\ldots+\phi_{p} \rho_{k-p} \quad, \quad k>0$

Indicando por $\phi_{k j}$ ○ j-ésimo coeficiente de um processo AR $(\mathrm{K})$ de tal modo que $\phi_{K K}$ seja o último coeficiente, pode-se escrever, de acordo com (30):

$\rho_{j}=\phi_{k_{1}} \rho_{j-1}+\phi_{k_{2}} \rho_{j-2}+\ldots+\phi_{k_{k}} \rho_{j-k} \quad j=1,2, \ldots k$

com $\rho_{j}=\rho_{-j}$, tem-se, para $j=1,2, \ldots, k$ : 
41

$$
\begin{aligned}
& \rho_{1}=\phi_{k 1}+\phi_{k 2} \rho_{1}+\phi_{k 3} \rho_{2}+\ldots+\phi_{k k} \rho_{k-1} \\
& \rho_{2}=\phi_{k 1} \rho_{1}+\phi_{k 2}+\phi_{k 3} \rho_{1}+\ldots+\phi_{k k} \rho_{k-2} \\
& \ldots \ldots \ldots \ldots \ldots \ldots \ldots \ldots \ldots \ldots \ldots \ldots \ldots \ldots \ldots \ldots \ldots \ldots \ldots \ldots \ldots \ldots \ldots \ldots \ldots \ldots \ldots \ldots \ldots \ldots \ldots \\
& \rho_{k}=\phi_{k 1} \rho_{k-1}+\phi_{k} \rho_{k-2}+\phi_{k_{3}} \rho_{k-3}+\ldots+\phi_{k k}
\end{aligned}
$$

A solução desse sistema é dado por:

$$
\left[\begin{array}{ccccc}
1 & \rho_{1} & \rho_{2} & \ldots & \rho_{k-1} \\
\rho_{1} & 1 & \rho_{1} & \ldots & \rho_{k-2} \\
\cdot & & & & \cdot \\
\cdot & & & & \cdot \\
\rho_{k-1} & \rho_{k-2} & \rho_{k-3} & \ldots & 1
\end{array}\right] \times\left[\begin{array}{c}
\phi_{k 1} \\
\phi_{k 2} \\
\cdot \\
\cdot \\
\phi_{k k}
\end{array}\right]=\left[\begin{array}{c}
\rho_{1} \\
\rho_{2} \\
\cdot \\
\cdot \\
\rho_{k}
\end{array}\right]
$$

segue-se que:

$$
\phi_{11}=\rho_{11}
$$

$$
\phi_{22}=\frac{\left|\begin{array}{cc}
1 & \rho_{1} \\
\rho_{1} & \rho_{2}
\end{array}\right|}{\left|\begin{array}{cc}
1 & \rho_{1} \\
\rho_{1} & 1
\end{array}\right|}=\frac{\rho_{2}-\rho_{1}^{2}}{1-\rho_{1}^{2}}
$$

$$
\phi_{33}=\frac{\left|\begin{array}{ccc}
1 & \rho_{1} & \rho_{1} \\
\rho_{1} & 1 & \rho_{2} \\
\rho_{2} & \rho_{1} & \rho_{3}
\end{array}\right|}{\left|\begin{array}{ccc}
1 & \rho_{1} & \rho_{2} \\
\rho_{1} & 1 & \rho_{1} \\
\rho_{2} & \rho_{1} & 1
\end{array}\right|}, \text { etc }
$$


e, em geral:

$\phi_{k k}=\frac{P_{k}^{*}}{P_{k}}$

onde $P_{k}$ é o determinante da matriz de autocorrelações e $P_{k}^{*}$ é o determinante da matriz de autocorrelações com a última coluna substituída pelo vetor:

$$
\left[\begin{array}{c}
\rho_{1} \\
\rho_{2} \\
\cdot \\
\cdot \\
\rho_{n}
\end{array}\right]
$$

Assim como no caso da autocorrelação é possivel estimar as autocorrelações parciais para a série de resíduos $\left(a_{k}\right)$. Para avaliar se os residuos das regressões estimadas não apresentavam dependência serial utilizou-se, além das autocorrelações e autocorrelações parciais, o teste de Durbin-Watson e o teste de $Q$ de Lijung-box. Esse último teste, que é aplicado às primeiras autocorrelções dos resíduos é dado por:

$$
Q(K)=n(n+2)\left[\sum_{K=1}^{K} \frac{1}{n-K} r_{K}^{2}(\hat{a})\right]
$$

Com distribuição de $X^{2}$. 


\section{Análise dos Resultados:}

\subsection{Determinação do Número de Defasagens}

O número de defasagens nos modelos utilizados para o teste de causalidade foi determinado com base na significância dos coeficientes dos valores futuros e passados da variável explicativa e nos resultados dos testes de AIC-Akaike e SC-Schwarz. Embora estes testes não sejam específicos para a definição do número de defasagens a serem utilizados em testes de causalidade, eles foram usados no sentido de oferecer uma orientação sobre a duração do efeito de perturbações sofridas pelas próprias séries em tempo passado. Os testes de AIC e SC podem ser expressos da seguinte forma:

$A I C(p)=\ln \tilde{\sigma}^{2}+(2 / T) \quad$ (número de parâmetros)

$S C(p)=\ln \hat{\sigma}^{2}+(2 \ln 1 / T)$ (número de parâmetros)

$\wedge 2$

Com $\hat{\sigma}$ sendo a soma dos quadrados dos resíduos dividida por $\mathrm{T}$ (número de observações). Partindo-se de uma especificação geral, com 30 defasagens, por exemplo no caso de séries diárias, são feitos ajustamentos sucessivos tomando-se como modelo mais adequado aquele que apresentar o menor valor para os critérios AIC e SC (LÜTKERPOHL, 1991). 
Os resultados dos testes de Akaike e de Schuwarz estão apresentados na tabela 2:

Tabela 2: Resultados dos teste de Akaike e Schwarz

\begin{tabular}{l|cc}
\hline Origem dos Preços & Akaike & Schwarz \\
\hline Carne (Gr. SP) & 9 & 1 \\
Indicador de Preços - SP & 7 & 2 \\
Araçatuba & 8 & 2 \\
Bauru/Marília & 5 & 1 \\
Pres. Prudente & 3 & 3 \\
S.J.Rio Preto & 14 & 2 \\
Três Lagoas & 6 & 2 \\
Campo Grande & 4 & 2 \\
Goiás & 16 & 1 \\
Trian. Mineiro & 3 & 1 \\
\hline
\end{tabular}

Os resultados dos testes apresentaram valores bastante conflitantes. A solução encontrada foi ajustar modelos com os valores sugeridos nos testes e verificar a significância dos coeficientes, mantendo-se para análise aqueles que apresentassem o coeficiente relativo à última defasagem significativo. Ajustou-se ainda, modelos com 5 
defasagens, considerando-se o fato de que estar-se tratando do período de uma semana (5 dias úteis).

Os resultados dos vários modelos ajustados para análise de causalidade estão apresentados nas tabelas 3 a 21 . As variáveis utilizadas são as seguintes:

$\mathrm{P}_{\text {car }} \rightarrow$ logaritmo do preço da carne bovina na região da grande São Paulo.

$\mathrm{P}_{\mathrm{Ar}} \rightarrow$ logaritmo do preço da arroba do boi gordo na região de Araçatuba/SP.

$\mathrm{P}_{\mathrm{B} / \mathrm{M}} \rightarrow$ logaritmo do preço da arroba gordo de boi na região de Bauru e Marília/SP.

$\mathrm{P}_{\mathrm{PP}} \rightarrow$ logaritmo do preço da arroba de boi gordo na região de Presidente Prudente/SP.

$P_{\text {SJRP }} \rightarrow$ logaritmo do preço da arroba de boi gordo na região de S. J. do Rio Preto/SP.

$P_{\mathrm{TL}} \rightarrow$ logaritmo do preço da arroba de boi gordo na região de Três Lagoas/MS.

$\mathrm{P}_{\mathrm{CG}} \rightarrow$ logaritmo do preço da arroba do boi gordo na região de Campo Grande/MS.

$\mathrm{P}_{\mathrm{TM}} \rightarrow$ logaritmo do preço da arroba do boi gordo na região do Triângulo Mineiro/MG.

$\mathrm{P}_{\mathrm{GO}} \rightarrow$ logaritmo do preço da arroba do boi gordo no estado de Goiás.

$P_{\text {Ind }} \rightarrow$ logaritmo do Indicador de Preços do boi gordo ESALQ/BM\&F/ SP.

Os resultados do teste $F$, embora sejam significativos em muitos dos modelos, devem ser interpretados com ressalvas nos casos em que observou-se um valor elevado do teste $Q$ de Qjung-Box (significativo a menos de $10 \%$ ). Isto indica que a série possui algum grau de autocorrelação nos resíduos, o que fere uma condição básica do teste. Convém ressaltar, no entanto, que apesar do teste $Q$ apresentar-se significativo as 
autocorrelações de resíduos individuais não se apresentaram significativas na maioria dos casos.

Nas tabelas de 3 a 7 estão apresentados os resultados dos testes de causalidade envolvendo os preços da carne bovina na região da Grande São Paulo, os preços da arroba de boi gordo nas regiões de Araçatuba, Presidente Prudente, São José do Rio Preto e Bauru/Marília, e também o Indicador de Preços BM\&F/ESALQ.

A tabela 8 apresenta a relação entre o preço do boi na região de Três Lagoas/MS e os preços da carne na Grande São Paulo. Nesta região do estado são encontrados vários escritórios de representação de frigoríficos paulistas, sendo, portanto, uma região que fornece animais vivos para serem abatidos no estado de São Paulo. A tabela 9 apresenta os resultados dos testes de causalidade envolvendo o preço da carne na grande São Paulo e o preço do boi em Campo Grande. Esta região, por estar situada mais distante do estado de São Paulo, é considerada uma região fornecedora de carne e não de animais vivos.

$\mathrm{Na}$ tabela 10 estão apresentados os resultados dos testes envolvendo o preço da arroba de boi gordo no estado de Goiás e o preço da carne na cidade de São Paulo. Esta região possui escritórios de compra de frigoríficos paulistas que disputam os animais com os frigoríficos situados na própria região. $\mathrm{Na}$ tabela 11 estão os resultados das análises envolvendo o preço da arroba na região do Triângulo Mineiro e o da arroba de carne no atacado na região da grande São Paulo. Esta região, pela proximidade geográfica, tem muitos compradores de frigoríficos paulistas. 
Os resultados apresentados nas tabelas 3 a 11 tratam de testes de causalidade entre preços em níveis de comercialização distintos, ou seja, entre o preço de carne no atacado, (preço que o frigorífico obtém quando faz a venda de carne na forma de traseiro, dianteiro e ponta de agulha) e o preço que ele paga ao produtor quando da aquisição de animais para abate.

As tabelas 3 a 7 trazem resultados das relações causais entre preços de regiões situadas no estado de São Paulo, que gozam portanto das mesmas regras tributárias. As tabelas 8 a 11 apresentam os resultados das relações causais entre os preços da carne vendida no estado de São Paulo e o preço da arroba do boi comercializado em Mato Grosso do Sul, Goiás, Minas Gerais. Nestes casos cada estado dispõe de regras de tributação próprias, como já descritas anteriormente.

Nas tabelas de 12 a 15 são analisadas as relações causais envolvendo o indicador de preços ESALQ/BM\&F e os preços da arroba de boi nas regiões de Três Lagoas, Campo Grande, Goiás e no Triângulo Mineiro. São analisadas nesses casos, as relações de preços entre regiões distintas mas do produto num mesmo nível de comercialização. 


\subsection{Resultados dos testes de Causalidade: Preços da Carne e os Preços de Boi gordo}

Neste tópico estão sendo analisados os resultados dos testes de causalidade que envolvem o preço da carne na região da Grande São Paulo e os preços de boi gordo nas regiões de Araçatuba, Presidente Prudente, São José do Rio Preto e Bauru/Marília, no estado de São Paulo, Campo Grande e Tres Lagoas em Mato Grosso do Sul, no estado de Goiás e na região do Triângulo Mineiro.

Os resultados apresentados na tabela 3 sugerem que há relação bi-causal entre o preço da carne na região da Grande São Paulo e o preço da arroba do boi na região de Araçatuba. No entanto, apenas no sentido do preço de carne para o preço do boi obtevese valores do $Q$ não significativos até 0,10 de probabilidade. Nos outros modelos, embora os resultados do teste de $\mathrm{F}$ sejam significativos, os resultados do teste de $\mathrm{Q}$ apontam para uma análise mais cautelosa quanto a existência de causalidade. 
Tabela 3: Testes de causalidade entre os preços da Carne atacado grande São Paulo e Boi Gordo em Araçatuba

\begin{tabular}{l|cll}
\hline relação & defasagens & $Q^{*}$ & $F^{* *}$ \\
\hline $\mathrm{P}_{\text {car }} \rightarrow \mathrm{P}_{\text {Ar }}$ & 9 & $65,7312(0,00179)$ & $8,1098(0,000)$ \\
$\mathrm{P}_{\text {car }} \rightarrow \mathrm{P}_{\text {Ar }}$ & 2 & $59,8371(0,00755)$ & $31,3006(0,000)$ \\
$\mathrm{P}_{\text {car }} \rightarrow \mathrm{P}_{\text {Ar }}$ & 5 & $59,1357(0,008883)$ & $16,7551(0,000)$ \\
$\mathrm{P}_{\text {car }} \rightarrow \mathrm{P}_{\mathrm{Ar}}$ & 8 & $57,0165(0,1433527)$ & $9,79459(0,000)$ \\
$\mathrm{P}_{\mathrm{Ar}} \rightarrow \mathrm{P}_{\text {car }}$ & 9 & $49,3459(0,068306)$ & $3,3214(0,0006314)$ \\
$\mathrm{P}_{\mathrm{Ar}} \rightarrow \mathrm{P}_{\text {car }}$ & 8 & $47,4159(0,09652)$ & $3,8550(0,000217)$ \\
$\mathrm{P}_{\mathrm{Ar}} \rightarrow \mathrm{P}_{\text {car }}$ & 5 & $36,6104(0,0001863)$ & $9,58609(0,000328)$ \\
$\mathrm{P}_{\text {Ar }} \rightarrow \mathrm{P}_{\text {car }}$ & 2 & $74,1695(0,0001863)$ & $9,5860(0,00084)$ \\
\hline
\end{tabular}

* entre parênteses, ao lado da estatística de Q, é apresentado nível de significância.

** entre parênteses, ao lado do resultado do teste de $F$, é apresentado o nivel de significância.

A tabela 4 apresenta os resultados das relações entre os preços da arroba de boi gordo na região de Bauru/Marilia e o preço da carne na grande São Paulo. Os resultados mostram que existe uma relação causal entre o preço da carne bovina e os preços da arroba de boi gordo $\left(\mathrm{P}_{\mathrm{car}} \rightarrow \mathrm{P}_{\mathrm{B} / \mathrm{M}}\right)$ na região de Bauru/Marilia. $\mathrm{O}$ modelo que oferece o melhor resultado é o com duas defasagens. Neste caso, o valor do $Q$ é menor e significativo apenas a niveis superiores a 0,10 de probabilidade, embora em todas as defasagens testadas o valor de $\mathrm{F}$ seja significativo. 
Tabela 4: Testes de causalidade entre os preços da Carne atacado na Grande São Paulo e do Boi Gordo em Bauru e Marília

\begin{tabular}{l|cll}
\hline relação & defasagens & $Q^{*}$ & $F^{* *}$ \\
\hline $\mathrm{P}_{\mathrm{car}} \rightarrow \mathrm{P}_{\mathrm{B} / \mathrm{m}}$ & 9 & $57,3743(0,0132)$ & $9,2225(0,000)$ \\
$\mathrm{P}_{\mathrm{car}} \rightarrow \mathrm{P}_{\mathrm{B} / \mathrm{m}}$ & 5 & $52,1668(0,00755)$ & $17,5101(0,000)$ \\
$\mathrm{P}_{\mathrm{car}} \rightarrow \mathrm{P}_{\mathrm{B} / \mathrm{m}}$ & 2 & $43,1367(0,1925)$ & $34,4628(0,000)$ \\
$\mathrm{P}_{\mathrm{B} / \mathrm{M}} \rightarrow \mathrm{P}_{\mathrm{car}}$ & 9 & $270,5498(0,000)$ & $1,2027(0,2915)$ \\
$\mathrm{P}_{\mathrm{B} / \mathrm{M}} \rightarrow \mathrm{P}_{\mathrm{car}}$ & 5 & $412,3567(0,000)$ & $4,7265(0,000328)$ \\
$\mathrm{P}_{\mathrm{B} / \mathrm{M}} \rightarrow \mathrm{P}_{\mathrm{car}}$ & 2 & $1335,1561(0,000)$ & $0,2033(0,8161)$ \\
\hline
\end{tabular}

* entre parênteses, ao lado da estatística de Q, é apresentado nível de significância.

${ }^{* *}$ entre parênteses, ao lado do resultado do teste de $F$, é apresentado o nível de significância.

Causalidade no sentido de preço da arroba de boi gordo na região de Bauru/Marilia para o preço da carne na Grande São Paulo só se verificou com o modelo com 5 defasagens. A existência de causalidade nesse sentido $\left(P_{B / M} \rightarrow P_{c a r}\right)$ parece difícil, visto, tratar-se de uma região de pouca importância em termos de produção.

A tabela 5 apresenta os resultados das relações causais entre o preço da carne e preço do boi gordo na região de Presidente Prudente. Os resultados apontam para a existência de relação bi-causal. No sentido $P_{c a r} \rightarrow P_{P P}$ todos os resultados do teste $F$ são significativos e os valores dos teste $Q$ apontam para a não existência de autocorrelação. 
Tabela 5: Testes de causalidade entre os preços da carne no atacado na Grande São Paulo e Boi Gordo em Presidente Prudente

\begin{tabular}{|c|c|c|c|}
\hline relação & defasagens & $Q$ & $F$ \\
\hline $\mathrm{P}_{\text {car }} \rightarrow \mathrm{P}_{\mathrm{PP}}$ & 3 & $37,2300(0,4122)$ & $29,8234(0,000)$ \\
\hline$P_{\text {car }} \rightarrow P_{P P}$ & 5 & $52,1668(0,3073)$ & $18,9922(0,000)$ \\
\hline $\mathrm{P}_{\text {car }} \rightarrow \mathrm{P}_{\mathrm{PP}}$ & 9 & $43,1367(0,3452)$ & $34,4628(0,000)$ \\
\hline $\mathrm{P}_{\mathrm{PP}} \rightarrow \mathrm{P}_{\mathrm{car}}$ & 3 & $38,9269(0,3393)$ & $9,3973(0,000005)$ \\
\hline $\mathrm{P}_{\mathrm{PP}} \rightarrow \mathrm{P}_{\text {car }}$ & 5 & $29,0659(0,7871)$ & $7,6813(0,000)$ \\
\hline $\mathrm{P}_{\mathrm{PP}} \rightarrow \mathrm{P}_{\mathrm{car}}$ & 9 & $31,0120(0,7046)$ & $4,7501(0,000005)$ \\
\hline
\end{tabular}

Na relação com sentido $P_{P P} \rightarrow P_{\text {car }}$ todos os modelos ajustados indicaram a existência de causalidade. Os resultados do teste de $F$ foram bastante significativos, e os resultados do teste de $Q$ apresentaram valores significativos só a níveis maiores que 0,10 .

A região de Presidente Prudente tem importância grande em termos de mercado. Trata-se de uma região que possue vastas áreas de pastagem e um número grande de comerciantes e escritórios de representação de frigorificos. Dessa forma, a região de Presidente Prudente é importante como formadora de preços, sendo essa condição reconhecida pelo mercado. 
Os resultados dos testes de causalidade entre o preço dos animais na região de São José do Rio Preto e o preço da carne na grande São Paulo (tabela 6) mostram a existência de causalidade bidirecional em todos os modelo ajustados. No entanto, somente em dois modelos, com defasagens de 9 e 14 dias, no sentido $P_{\text {car }} \rightarrow P_{\text {SJRP }}$, os resultados do teste de $Q$ apresentam valores cujos graus de significância estão acima de 0,10 de probapilidade.

Tabela 6: Testes de causalidade entre os preços da carne no atacado na grande São Paulo e boi gordo em S.J. do Rio Preto

\begin{tabular}{|c|c|c|c|}
\hline relação & defasagens & $Q^{*}$ & $F^{* \star}$ \\
\hline $\mathrm{P}_{\mathrm{car}} \rightarrow \mathrm{P}_{\text {SJRP }}$ & 14 & $42,7386(0,2041)$ & $6,9972(0,000)$ \\
\hline$P_{\text {car }} \rightarrow P_{\text {SJRP }}$ & 9 & $43,8532(0,1728)$ & $10,4557(0,000)$ \\
\hline$P_{\text {car }} \rightarrow P_{\text {SJRP }}$ & 5 & $48,8257(0,0751)$ & $17,9086(0,000)$ \\
\hline$P_{\text {car }} \rightarrow P_{\text {SJRP }}$ & 2 & $48,3091(0,0824)$ & $32,5264(0,000)$ \\
\hline$P_{\text {SJRP }} \rightarrow P_{\text {car }}$ & 14 & $55,9002(0,0183)$ & $5,7582(0,000)$ \\
\hline$P_{\text {SJRP }} \rightarrow P_{\text {car }}$ & 9 & $56,0002(0,0179)$ & $8,9434(0,000)$ \\
\hline$P_{\text {SJRP }} \rightarrow P_{\text {car }}$ & 5 & $57,3501(0,0133)$ & $16,5058(0,000)$ \\
\hline$P_{\text {SJRP }} \rightarrow P_{\text {car }}$ & 2 & $49,0626(0,0626)$ & $29,5490(0,000)$ \\
\hline
\end{tabular}

*entre parênteses, ao lado da estatística de Q, é apresentado nivel de significância.

${ }^{\star *}$ entre parênteses, ao lado do resultado do teste de $F$, é apresentado o nivel de significância.

Nos modelos que tratam de verificar a causalidade no sentido $P_{\text {SJRP }} \rightarrow P_{\text {car }}$, embora os resultados do teste $\mathrm{F}$ apresentam-se significativos, os resultados devem ser tomados com reservas, uma que o teste de $Q$ apresentou valores significativos a níveis inferiores a 0,10 de probabilidade, indicando a existência de autocorrelação. 
A região de São José do Rio Preto possui vários frigoríficos instalados e vários deles estão fechados. É uma região em que a área de pastagem perdeu espaço para outras culturas.

Praticamente todos os modelos definidos para a determinação da existência de causalidade entre o preço da carne $\left(\mathrm{P}_{\text {car }}\right)$ e o Indicador de Preços da arroba de boi gordo $\left(P_{\text {ind }}\right)$ (tabela7) apontam para uma relação bi-causal. No entanto, somente em três casos os modelos ajustados apresentam resíduos não correlacionados.

Tabela 7: Testes de causalidade entre os preços da carne no atacado na grande São Paulo e Indicador de Preços do Boi Gordo

\begin{tabular}{l|cll}
\hline relação & defasagens & $Q^{*}$ & $F^{\star \star}$ \\
\hline$P_{\text {car }} \rightarrow P_{\text {ind }}$ & 9 & $49,3348(0,0684)$ & $2,4194(0,0110)$ \\
$P_{\text {car }} \rightarrow P_{\text {ind }}$ & 7 & $43,6076(0,1794)$ & $2,5368(0,0145)$ \\
$P_{\text {car }} \rightarrow P_{\text {ind }}$ & 5 & $38,5223(0,3561)$ & $2,8561(0,0150)$ \\
$P_{\text {car }} \rightarrow P_{\text {ind }}$ & 2 & $45,9363(0,1240)$ & $0,0036(0,0963)$ \\
$P_{\text {ind }} \rightarrow P_{\text {car }}$ & 9 & $64,2960(0,0025)$ & $17,2169(0,000)$ \\
$P_{\text {ind }} \rightarrow P_{\text {car }}$ & 7 & $57,9670(0,0115)$ & $22,0125(0,000)$ \\
$P_{\text {ind }} \rightarrow P_{\text {car }}$ & 5 & $63,6638(0,0030)$ & $27,4390(0,000)$ \\
$P_{\text {ind }} \rightarrow P_{\text {car }}$ & 2 & $202,0850(0,000)$ & $25,7682(0,000)$ \\
\hline
\end{tabular}

* entre parênteses, ao lado da estatística de Q, é apresentado nivel de significância.

** entre parênteses, ao lado do resultado do teste de $F$, é apresentado o nível de significância. 
Os testes de causalidade com sentido $P_{\text {ind }} \rightarrow P_{\text {car }}$ com defasagens de ordem 7 , 5 e 2 foram os únicos que apresentaram os resultados do teste de $Q$ com valores significativos acima de 0,10 de probabilidade, sendo que aquele que mostrou um grau de significância mais elevado para o teste $Q$ foi o modelo com 5 defasagens. Dentre os modelos ajustados apenas único modelo com 2 defasagens apresentou resultado um pouco distinto dos demais, por que apresentou um resultado do teste de $F$ pouco significativo.

As relações com sentido de $\mathrm{P}_{\text {car }} \rightarrow \mathrm{P}_{\text {ind }}$ apresentaram resultados dos testes $\mathrm{F}$ significativos, indicando portanto a existência de causalidade. No entanto, em todos os modelos o teste de $Q$ apresentou valores significativos, o que indica que a autocorrelação não foi totalmente eliminada. Logo, os resultados desses testes devem ser analisados com essa ressalva. 
Tabela 8: Testes de causalidade entre os preços da carne no atacado grande São Paulo e Boi Gordo em Três Lagoas

\begin{tabular}{l|ccl}
\hline relação & defasagens & $Q^{*}$ & $F^{* *}$ \\
\hline $\mathrm{P}_{\text {car }} \rightarrow \mathrm{P}_{\mathrm{TL}}$ & 9 & $52,4901(0,3727)$ & $15,0467(0,000)$ \\
$\mathrm{P}_{\mathrm{car}} \rightarrow \mathrm{P}_{\mathrm{TL}}$ & 6 & $52,2216(0,0393)$ & $19,0599(0,000)$ \\
$\mathrm{P}_{\mathrm{car}} \rightarrow \mathrm{P}_{\mathrm{TL}}$ & 5 & $55,2203(0,0211)$ & $28,4137(0,000)$ \\
$\mathrm{P}_{\mathrm{car}} \rightarrow \mathrm{P}_{\mathrm{TL}}$ & 2 & $47,0361(0,1030)$ & $49,0601(0,000)$ \\
$\mathrm{P}_{\mathrm{TL}} \rightarrow \mathrm{P}_{\mathrm{car}}$ & 9 & $44,5302(0,1556)$ & $1,8100(0,0647)$ \\
$\mathrm{P}_{\mathrm{TL}} \rightarrow \mathrm{P}_{\mathrm{car}}$ & 6 & $45,2479(0,1388)$ & $2,9753(0,0074)$ \\
$\mathrm{P}_{\mathrm{TL}} \rightarrow \mathrm{P}_{\mathrm{car}}$ & 5 & $44,0009(0,1689)$ & $4,0689(0,0012)$ \\
$\mathrm{P}_{\mathrm{TL}} \rightarrow \mathrm{P}_{\mathrm{car}}$ & 2 & $51,7591(0,0431)$ & $9,6236(0,00008)$ \\
\hline
\end{tabular}

* entre parênteses, ao lado da estatística de Q, é apresentado nível de significância.

** entre parênteses, ao lado do resultado do teste de $F$, é apresentado o nivel de significância.

A tabela 8 apresenta os resultados dos modelos de teste de causalidade para o preço da arroba de boi gordo na região de Três Lagoas/MS e o da carne na grande São Paulo. Os resultados apontam para a existência de relações causais entre os preço em ambos os sentidos. No sentido $P_{c a r} \rightarrow P_{T L}$ os valores do teste de $F$ são significativos em todos os casos, mas somente nos modelos com defasagens de ordens 2 e 9 os resultados do teste de $Q$ são não significativos até 0,10 de probabilidade.

Todas as relações com sentido $\mathrm{P}_{\mathrm{TL}} \rightarrow \mathrm{P}_{\text {car }}$ apresentaram valores significativos para o teste de $\mathrm{F}$ e somente para defasagem de ordens 2 os resultados do teste de $\mathrm{Q}$ apresentaram valores significativos a menos de 0,10 de probalidade. Esta região é 
bastante próxima da região de Araçatuba, que é responsável por uma considerável capacidade de abate do estado de São Paulo.

Os resultados do teste de causalidade entre os preços da carne e do boi gordo na região de Campo Grande (tabela 9) apresentaram resultados conflitantes quando ao sentido de causalidade $P_{\text {car }} \rightarrow P_{C G}$. Dependendo das defasagem do modelo os resultados dos testes $\mathrm{F}$ apresentam-se significativos ou não. Considerando o sentido inverso $\left(\mathrm{P}_{\mathrm{CG}} \rightarrow \mathrm{P}_{\text {car }}\right)$ obteve-se resultados do teste de $\mathrm{F}$ com significância acima de 0,10 de probabilidade, ou seja, pode-se dizer que não há causalidade nesse sentido. Os resultados do teste de $Q$ também são significativos acima de 0,10 de probabilidade.

Tabela 9: Testes de causalidade entre os preços da carne no atacado na grande São Paulo e do Boi Gordo em Campo Grande

\begin{tabular}{l|cll}
\hline relação & defasagens & $Q^{*}$ & $F^{\star *}$ \\
\hline$P_{\text {car }} \rightarrow P_{C G}$ & 9 & $28,0580(0,8251)$ & $1,4430(0,1783)$ \\
$P_{c a r} \rightarrow P_{C G}$ & 5 & $35,3641(0,4986)$ & $3,9426(0,0038)$ \\
$P_{c a r} \rightarrow P_{C G}$ & 4 & $32,6024(0,6309)$ & $2,6823(0,0467)$ \\
$P_{c a r} \rightarrow P_{C G}$ & 2 & $37,0715(0,4193)$ & $4,4678(0,0120)$ \\
$P_{C G} \rightarrow P_{c a r}$ & 9 & $33,0478(0,7468)$ & $1,1701(0,3160)$ \\
$P_{C G} \rightarrow P_{c a r}$ & 5 & $30,0478(0,7468)$ & $1,2547(0,2873)$ \\
$P_{C G} \rightarrow P_{c a r}$ & 4 & $29,0336(0,7883)$ & $1,3085(0,2712)$ \\
$P_{C G} \rightarrow P_{c a r}$ & 2 & $29,0879(0,7862)$ & $2,1030(0,1234)$
\end{tabular}

* entre parênteses, ao lado da estatística de $Q$, é apresentado nível de significância.

** entre parênteses, ao lado do resultado do teste de $F$, é apresentado o nivel de significância. 
A tabela 10 apresenta os resultados dos testes de causalidade entre os preços da carne no atacado $\left(P_{\text {car }}\right)$ e o preços do boi gordo em Goiás $\left(P_{G O}\right)$. Os resultados encontrados apontam para a existência de causalidade em ambos sentidos, ou seja, há relação bi-causal entre esses preços. Na relação com sentido $P_{\text {car }} \rightarrow P_{G O} \circ$ resultado do teste de $Q$ apresentou nível de significância acima de 0,10 de probabilidade em três modelos: com 2, 5 e 16 defasagens. O modelo que tem melhor ajustamento é o com 5 defasagem. Neste modelo o teste de $Q$ apresentou o maior nivel grau de significância $(0,20 \%$ de probabilidade $)$.

Tabela 10: Testes de causalidade entre os preços da carne no atacado na grande São Paulo e do Boi Gordo em Goiás

\begin{tabular}{l|cll}
\hline relação & defasagens & $Q^{*}$ & $F^{\star \star}$ \\
\hline$P_{\text {car }} \rightarrow P_{G O}$ & 16 & $46,0178(0,1224)$ & $7,1645(0,000)$ \\
$P_{c a r} \rightarrow P_{G O}$ & 9 & $47,4478(0,0959)$ & $12,5969(0,000)$ \\
$P_{c a r} \rightarrow P_{G O}$ & 5 & $42,8045(0,2021)$ & $37,2450(0,000)$ \\
$P_{c a r} \rightarrow P_{G O}$ & 2 & $43,5200(0,1818)$ & $37,2450(0,000)$ \\
$P_{G O} \rightarrow P_{c a r}$ & 16 & $56,9243(0,0146)$ & $2,4619(0,0018)$ \\
$P_{G O} \rightarrow P_{c a r}$ & 9 & $57,3852(0,0132)$ & $2,8947(0,0038)$ \\
$P_{G O} \rightarrow P_{c a r}$ & 5 & $57,0118(0,0143)$ & $2,7744(0,0268)$ \\
\hline
\end{tabular}

* entre parênteses, ao lado da estatística de Q, é apresentado nível de significância.

** entre parênteses, ao lado do resultado do teste de $F$, é apresentado o nivel de significância.

Os preços do estado de Goiás são influenciados pelos compradores de frigorificos paulistas, sendo a presença destes mais comum na região sul do estado. A 
influencia de compradores de frigoríficos paulistas não é tão marcante quanto na região de Três Lagoas, mas acirra a concorrência com os frigorificos da própria região.

Os resultados dos testes de causalidade no sentido $P_{G O} \rightarrow P_{c a r}$, embora também apresentem resultados que apontam para a existência de causalidade, devem ser tomados com reservas, uma vez que os resultados dos teste $Q$ apresentam-se significativos a menos de 0,10 de probabilidade, o que leva a supor que nem toda a autocorrelação dos resíduos foi eliminada.

$\mathrm{Na}$ tabela 11 são apresentados os resultados dos testes de causalidade entre o preço da carne na grande São Paulo e o preço da arroba de boi gordo na região do Triângulo Mineiro. Verifica-se relação bi-causal entre esses preços. No sentido do preço do boi gordo para preço da carne $\left(P_{T M} \rightarrow P_{\text {car }}\right)$ os resultados devem ser analisados com certas precaução, pois os resultados dos testes $Q$ são significativos a mais de 0,10 de probabilidade. No sentido inverso $\left(P_{c a r} \rightarrow P_{T M}\right)$ os resultados dos testes não apresentam esse tipo de problema, com excessão do resultado do modelo com 5 defasagens. 
Tabela 11: Testes de causalidade entre os preços da carne no atacado na grande São Paulo e do boi gordo no Triângulo Mineiro

\begin{tabular}{l|ccl}
\hline relação & defasagens & $\mathrm{Q}^{*}$ & $\mathrm{~F}^{* *}$ \\
\hline $\mathrm{P}_{\mathrm{car}} \rightarrow \mathrm{P}_{\mathrm{TM}}$ & 9 & $47,1525(0,1010)$ & $12,6663(0,000)$ \\
$\mathrm{P}_{\mathrm{car}} \rightarrow \mathrm{P}_{\mathrm{TM}}$ & 5 & $47,4535(0,0959)$ & $23,5709(0,000)$ \\
$\mathrm{P}_{\mathrm{car}} \rightarrow \mathrm{P}_{\mathrm{TM}}$ & 3 & $42,0493(0,2253)$ & $34,8050(0,000)$ \\
$\mathrm{P}_{\mathrm{car}} \rightarrow \mathrm{P}_{\mathrm{TM}}$ & 2 & $47,0767(0,1023)$ & $45,7099(0,000)$ \\
$\mathrm{P}_{\mathrm{TM}} \rightarrow \mathrm{P}_{\mathrm{car}}$ & 9 & $59,9701(0,0073)$ & $2,1046(0,0282)$ \\
$\mathrm{P}_{\mathrm{TM}} \rightarrow \mathrm{P}_{\mathrm{car}}$ & 5 & $73,3133(0,0001)$ & $4,0501(0,0013)$ \\
$\mathrm{P}_{\mathrm{TM}} \rightarrow \mathrm{P}_{\mathrm{car}}$ & 3 & $73,3133(0,0002)$ & $7,1475(0,0001)$ \\
$\mathrm{P}_{\mathrm{TM}} \rightarrow \mathrm{P}_{\mathrm{car}}$ & 2 & $128,8029(0,000)$ & $8,44379(0,0002)$ \\
\hline
\end{tabular}

O Triângulo Mineiro é uma região onde vários frigoríficos paulistas atuam comprando animais para abate. Além disso deve-se considerar o fato de que na região existem empresas controladas por frigoríficos paulistas. 


\subsection{Resultados dos testes de Causalidade: Preços da Arroba de Boi Gordo fora do estado de São Paulo e o Indicador de Preços ESALQ/BM\&F (SP)}

Nas tabelas seguintes os testes de causalidade não mais tratam de níveis de consumo diferentes, mas sim do mesmo produto em regiões diferentes. $O$ preço médio do estado de São Paulo, representado pelo indicador de preços ESALQ/BM\&F é testado em relação a cada uma das regiões que tem alguma influência nos preços da carne no mercado paulista.

Tabela 12: Testes de causalidade entre o Indicador de Preços e os preços boi gordo em Três Lagoas (MS)

\begin{tabular}{|c|c|c|c|}
\hline relação & defasagens & $Q^{*}$ & $F^{* *}$ \\
\hline$P_{\text {Ind }} \rightarrow P_{T L}$ & 7 & $38,5218(0,3561)$ & $23,5580(0,000)$ \\
\hline $\mathrm{P}_{\text {Ind }} \rightarrow \mathrm{P}_{\mathrm{TL}}$ & 5 & $44,6806(0,1519)$ & $32,8316(0,000)$ \\
\hline $\mathrm{P}_{\text {Ind }} \rightarrow \mathrm{P}_{\mathrm{TL}}$ & 3 & $43,6506(0,1782)$ & $55,9538(0,000)$ \\
\hline $\mathrm{P}_{\text {Ind }} \rightarrow \mathrm{P}_{\mathrm{TL}}$ & 2 & $42,6518(0,2067)$ & $85,3732(0,000)$ \\
\hline $\mathrm{P}_{\mathrm{TL}} \rightarrow \mathrm{P}_{\text {Ind }}$ & 7 & $32,6408(0,6291)$ & $1,9984(0,0541)$ \\
\hline $\mathrm{P}_{\mathrm{TL}} \rightarrow \mathrm{P}_{\mathrm{Ind}}$ & 5 & $41,7927(0,2336)$ & $2,3495(0,0403)$ \\
\hline $\mathrm{P}_{\mathrm{TL}} \rightarrow \mathrm{P}_{\text {Ind }}$ & 3 & $41,8893(0,2305)$ & $3,7420(0,0112)$ \\
\hline $\mathrm{P}_{\mathrm{TL}} \rightarrow \mathrm{P}_{\mathrm{Ind}}$ & 2 & $40,5691(0,2758)$ & $4,5168(0,0114)$ \\
\hline
\end{tabular}

${ }^{*}$ entre parênteses, ao lado da estatística de Q, é apresentado nível de significância.

** entre parênteses, ao lado do resultado do teste de $F$, é apresentado o nivel de significância.

A tabela 12 apresenta os resultados dos testes envolvendo o Indicador de Preços e os preços do boi na região de Três Lagoas/MS. Os resultados apontam para uma 
relação bi-causal, sendo o teste $F$ significativos em ambos os casos. Os valores de $F$ para o sentido $P_{\text {Ind }} \rightarrow P_{T L}$ são mais elevados e os resultado do teste de $Q$ também são significativos acima de $10 \%$. Dentre os modelos especificados o que melhor ajustou-se, tomando o teste $\mathrm{Q}$ significativo acima de $10 \%$ como parâmetro, é o modelo que apresenta 7 dias de defasagem. No sentido inverso $\left(P_{T L} \rightarrow P_{\text {Ind }}\right)$ os resultados do teste de $F$ são menores e significativos. O modelo que apresenta melhor ajuste, que também é obtido com 7 dias de defasagem, apresenta o resultado do teste $Q$ significativo a 0,62 de probabilidade, com o resultados do teste de $\mathrm{F}$ significativo a 0,05 de probabilidade.

Esta região está situada na divisa entre os estados de São Paulo e Mato Grosso do Sul, portanto oferece vantagens em termos de distância para os frigoríficos paulistas, principalmente aqueles situados na região de Araçatuba. A atuação das empresas paulistas nessa região é muito forte, além disso as políticas fiscais de ambos os estados acabam sempre tendo muita influência nos frigorificos que atuam nesse intercâmbio. Como um exemplo dessas ações tem-se: o estado do Mato Grosso do Sul eleva o valor da pauta, elevando o valor do ICMS a ser recolhido. Com isso os frigorificos paulistas ficam fora do mercado, os preços no mercado local começam a cair e os frigoríficos da região se beneficiam, pois compram os animais por um preço menor e vendem a carne pelo mesmo preço que os paulistas. Aos frigoríficos paulistas resta a opção de comprar os animais no próprio estado de pagar mais pela arroba. 
Tabela 13: Testes de causalidade entre o Indicador de Preços e os preços da arroba de boi gordo em Campo Grande (MS)

\begin{tabular}{l|cll}
\hline relação & defasagens & $Q^{*}$ & $F^{* *}$ \\
\hline$P_{\text {Ind }} \rightarrow P_{C G}$ & 7 & $34,5107(0,5394)$ & $19,0123(0,000)$ \\
$P_{\text {Ind }} \rightarrow P_{C G}$ & 5 & $34,8285(0,5241)$ & $26,8840(0,000)$ \\
$P_{\text {Ind }} \rightarrow P_{C G}$ & 4 & $37,2653(0,4106)$ & $34,8636(0,000)$ \\
$P_{\text {Ind }} \rightarrow P_{C G}$ & 2 & $32,6994(0,6263)$ & $59,4531(0,000)$ \\
$P_{C G} \rightarrow P_{\text {Ind }}$ & 7 & $34,5107(0,5394)$ & $19,0123(0,000)$ \\
$P_{C G} \rightarrow P_{\text {Ind }}$ & 5 & $34,8285(0,5241)$ & $26,8840(0,000)$ \\
$P_{C G} \rightarrow P_{\text {Ind }}$ & 4 & $37,2873(0,4096)$ & $4,3000(0,0020)$ \\
$P_{C G} \rightarrow P_{\text {Ind }}$ & 2 & $32,9846(0,6127)$ & $7,7522(0,0004)$ \\
\hline
\end{tabular}

* entre parênteses, ao lado da estatística de Q, é apresentado nível de significância.

** entre parênteses, ao lado do resultado do teste de $F$, é apresentado o nível de significância.

$\mathrm{Na}$ tabela 13 estão apresentados os resultados dos modelos que estimam as relações causais entre o indicador de preço e o preço da arroba de boi na região de Campo Grande. Em todos os casos os resultados do teste de $\mathrm{F}$ apontam para existência de relação bi-causal. Analisando-se os resultados do teste de $Q$, considerou-se o modelo que melhor se ajustou aquele com 2 dias de defasagens. No sentido $P_{\text {Ind }} \rightarrow P_{C G}$ os resultados do teste de $F$ são bem mais elevados e os testes $Q$ são significativo a um nível de $0,63 \%$. 
No sentido inverso $\left(P_{C G} \rightarrow P_{\text {Ind }}\right)$ os resultados do teste de $F$ apresentam valores menores e o modelo que mais se ajustou apresenta o resultado do teste $Q$ significativo a $0,61 \%$.

A região de Campo Grande não tem compradores de frigoríficos paulistas, pois a distância é apontada como um fator limitante dado os diferenciais de preço. Esta região é vista como importante fornecedora de carne.

Tabela 14: Testes de causalidade entre o Indicador de Preços da arroba de boi e os preços da arroba de boi gordo no Triângulo Mineiro (MG)

\begin{tabular}{l|ccl}
\hline relação & defasagens & $Q^{*}$ & $F^{\star *}$ \\
\hline $\mathrm{P}_{\text {ind }} \rightarrow \mathrm{P}_{\mathrm{TM}}$ & 7 & $39,5735(0,3134)$ & $18,0932(0,000)$ \\
$\mathrm{P}_{\text {ind }} \rightarrow \mathrm{P}_{\mathrm{TM}}$ & 5 & $40,1856(0,2900)$ & $25,1954(0,000)$ \\
$\mathrm{P}_{\text {ind }} \rightarrow \mathrm{P}_{\mathrm{TM}}$ & 3 & $36,5576(0,4427)$ & $42,6723(0,000)$ \\
$\mathrm{P}_{\text {ind }} \rightarrow \mathrm{P}_{\mathrm{TM}}$ & 2 & $36,7252(0,4350)$ & $66,3514(0,000)$ \\
$\mathrm{P}_{\mathrm{TM}} \rightarrow \mathrm{P}_{\text {ind }}$ & 7 & $69,3829(0,0006)$ & $2,4204(0,0194)$ \\
$\mathrm{P}_{\mathrm{TM}} \rightarrow \mathrm{P}_{\text {ind }}$ & 5 & $70,8237(0,0004)$ & $3,7501(0,0024)$ \\
$\mathrm{P}_{\mathrm{TM}} \rightarrow \mathrm{P}_{\text {ind }}$ & 3 & $72,1425(0,0003)$ & $5,6428(0,0008)$ \\
$\mathrm{P}_{\mathrm{TM}} \rightarrow \mathrm{P}_{\text {ind }}$ & 2 & $71,0844(0,0003)$ & $7,4741(0,0006)$ \\
\hline
\end{tabular}

* entre parênteses, ao lado da estatística de Q, é apresentado nível de significância.

** entre parênteses, ao lado do resultado do teste de $F$, é apresentado o nivel de significância. 
Os resultados dos testes $\mathrm{F}$ apontam para existência de bi-causalidade entre os preços da região do Triângulo Mineiro e o Indicador de Preços. Nos modelos em que é testada a relação no sentido $P_{\text {ind }} \rightarrow P_{T M}$ os resultados do teste $Q$ são significativos a mais de $0,10 \%$ de probabilidade, ou seja, a autocorrelação é eliminada.

Nos teste envolvendo as relações no sentido inverso $P_{T M} \rightarrow P_{\text {ind }}$ os resultados do teste $Q$ são significativos a menos de $10 \%$; logo os resultados devem ser observados com a ressalva de que há autocorrelação dos residuos.

Tabela 15: Testes de causalidade entre o Indicador de Preços da arroba da carne e os preços da arroba de boi gordo em Goiás

\begin{tabular}{l|ccl}
\hline relação & defasagens & $Q^{*}$ & $F^{* *}$ \\
\hline $\mathrm{P}_{\text {ind }} \rightarrow \mathrm{P}_{\mathrm{GO}}$ & 16 & $40,8761(0,2648)$ & $10,5127(0,000)$ \\
$\mathrm{P}_{\text {ind }} \rightarrow \mathrm{P}_{\mathrm{GO}}$ & 7 & $34,7211(0,5293)$ & $23,0368(0,000)$ \\
$\mathrm{P}_{\text {ind }} \rightarrow \mathrm{P}_{\mathrm{GO}}$ & 5 & $34,1635(0,5561)$ & $31,7907(0,000)$ \\
$\mathrm{P}_{\text {ind }} \rightarrow \mathrm{P}_{\mathrm{GO}}$ & 2 & $38,1143(0,3734)$ & $82,5337(0,000)$ \\
$\mathrm{P}_{\mathrm{GO}} \rightarrow \mathrm{P}_{\text {ind }}$ & 16 & $34,1965(0,5545)$ & $2,3996(0,0025)$ \\
$\mathrm{P}_{\mathrm{GO}} \rightarrow \mathrm{P}_{\text {ind }}$ & 7 & $40,7291(0,2701)$ & $3,9701(0,0011)$ \\
$\mathrm{P}_{\mathrm{GO}} \rightarrow \mathrm{P}_{\text {ind }}$ & 5 & $41,5999(0,2400)$ & $4,1077(0,0011)$ \\
$\mathrm{P}_{\mathrm{GO}} \rightarrow \mathrm{P}_{\text {ind }}$ & 2 & $42,5425(0,2100)$ & $9,7801(0,000)$ \\
\hline
\end{tabular}

* entre parênteses, ao lado da estatística de Q, é apresentado nível de significância.

** entre parênteses, ao lado do resultado do teste de $F$, é apresentado o nível de significância. 
Nos testes de causalidade envolvendo os preços da arroba de boi no estado de Goiás e o Indicador de Preços detectou-se a existência de causalidade em ambos os sentidos. Os resultados dos testes $\mathrm{F}$ foram significativos em todos os modelos. Também em todos os casos os resultados do teste $Q$ foram significativos a mais de $0,10 \%$ de probabilidade indicando a eliminação de autocorrelação.

\subsection{Sintese dos Resultados}

Nas tabelas 3 a 7 são analisadas as relações causais entre preços de carne bovina na região da grande São Paulo e o preço da arroba de boi gordo em diferentes regiões do estado de São Paulo. Os modelos detectaram relação de causalidade em todas as direções, no entanto os melhores ajustamentos foram obtidos no sentido do preço da carne influenciando os preços do boi gordo. (resultados apresentados na tabela 16) 
Tabela 16: Resultados dos modelos com melhor ajuste do Testes Causalidade entre os preços da carne na Grande São Paulo e os Preços da arroba no Estado de São Paulo

\begin{tabular}{l|ccl}
\hline relação & defasagens & $\mathrm{Q}^{*}$ & $F^{* *}$ \\
\hline $\mathrm{P}_{\mathrm{car}} \rightarrow \mathrm{P}_{\mathrm{Ar}}$ & 8 & $57,0165(0,1433)$ & $9,7945(0,000)$ \\
$\mathrm{P}_{\mathrm{car}} \rightarrow \mathrm{P}_{\mathrm{B} M}$ & 2 & $43,1367(0,1925)$ & $34,4628(0,000)$ \\
$\mathrm{P}_{\mathrm{car}} \rightarrow \mathrm{P}_{\mathrm{PP}}$ & 3 & $37,2300(0,4122)$ & $29,8234(0,000)$ \\
$\mathrm{P}_{\mathrm{car}} \rightarrow \mathrm{P}_{\mathrm{SJRP}}$ & 14 & $42,7386(0,2041)$ & $6,9972(0,000)$ \\
$\mathrm{P}_{\mathrm{car}} \rightarrow \mathrm{P}_{\text {ind }}$ & 5 & $38,5223(0,3561)$ & $2,8561(0,0150)$ \\
\hline
\end{tabular}

* entre parênteses, ao lado da estatística de Q, é apresentado nivel de significância.

** entre parênteses, ao lado do resultado do teste de F, é apresentado o nível de significância.

Os números de defasagens relativos aos melhores ajustamentos foram diferentes para cada região. No caso indicador, que é uma média ponderada dos preços do boi no estado, o melhor ajustamento foi com cinco dias, ou seja, considerando-se a semana com cinco dias úteis, o intervalo de resposta é de uma semana. As regiões de São José do Rio Preto e de Araçatuba têm mais facilidade para trazer animais de fora do estado de São Paulo. A região de S.J. do Rio Preto tradicionalmente compra animais do Triângulo Mineiro e do estado de Goiás. A região de Araçatuba tem facilidade de buscar os animais no estado de Mato Grosso do Sul, mais especificamente na região de Três Lagoas. Para estas duas os melhores modelos ajustados foram com maior número de defasagens, ou seja, são regiões onde os efeitos das variações dos preços da carne influem por um prazo maior nos preços do animal para abate. 
Para as regiões de Bauru/Marília e de Presidente Prudente, os melhores ajustamentos se deram com modelos com prazos de defasagens de ordem 2 e 3 , ou seja, menores que cinco. A região de Bauru/Marilia é a mais próxima da Grande São Paulo e possui a menor capacidade de abate e em que a atividade é menos importante. A região de Presidente Prudente apresenta a segunda menor capacidade de abate, porém trata-se de um importante centro fornecedor de animais para abate.

Com base nesses resultados pode-se afirmar que os preços da carne na região da grande São Paulo têm influência na formação dos preços de todas as regiões de produção de bois do estado de São Paulo.

As relações em sentido inverso, ou seja, os preços do boi influenciando os preços da carne, apresentam um ajustamento pouco satisfatório. Esses resultados devem, portanto, ser analisados com cuidado, pois em três regiões não foi possivel eliminar as autocorrelações dos residuos, sendo os resultados do teste de $Q$ significativos a níveis inferiores a 0,10 de probabilidade. Os resultados das regiões de Araçatuba e de São José do Rio Preto apontam para a existência de causalidade. Para a região de Bauru/Marília não se verificou causalidade. Somente na região de Presidente Prudente foi possível eliminar a autocorrelação dos resíduos. Nesta região os resultados também apontam para a existência de causalidade. As regiões de Araçatuba e Presidente Prudente são vistas pelo mercado como regiões de grande importância em termos de formação dos preços do boi gordo, por isso é de se esperar que variações de preços nessas regiões influenciem o mercado. A região de S.J. do Rio Preto é muito importante em termos de capacidade instalada de abate, por esse motivo é de se esperar que influam nos preços. 
A região de Bauru/Marília é uma região de pouca tradição e expressão, por esse motivo é pouco provável que cause influência nos preços da carne.

Tabela 17: Resultados dos modelos com melhor ajuste do Testes Causalidade entre os preços da arroba no Estado de São Paulo e os preços da carne na Grande São Paulo

\begin{tabular}{|c|c|c|c|}
\hline relação & defasagens & $Q^{*}$ & $F^{\star *}$ \\
\hline $\mathrm{P}_{\mathrm{Ar}} \rightarrow \mathrm{P}_{\mathrm{car}}$ & 8 & $47,4159(0,0965)$ & $3,8550(0,0002)$ \\
\hline $\mathrm{P}_{\mathrm{B} / \mathrm{M}} \rightarrow \mathrm{P}_{\mathrm{car}}$ & 9 & $270,5498(0,000)$ & $1,2027(0,2915)$ \\
\hline $\mathrm{P}_{\mathrm{PP}} \rightarrow \mathrm{P}_{\text {car }}$ & 5 & $29,0659(0,7871)$ & $7,6813(0,000)$ \\
\hline $\mathrm{P}_{\text {SJRP }} \rightarrow \mathrm{P}_{\text {car }}$ & 2 & $49,0626(0,0626)$ & $29,5490(0,000)$ \\
\hline$P_{\text {ind }} \rightarrow P_{\text {car }}$ & 7 & $57,9670(0,0115)$ & $22,0125(0,000)$ \\
\hline
\end{tabular}

A oferta de carne na grande São Paulo origina da produção do próprio estado e fora deste. No caso do boi produzido e abatido no estado de São Paulo, o mercado de carne na capital é o principal destino. Os preços da carne na cidade de São Paulo constituem-se num importante referencial para os frigoríficos no momento da compra dos animais.

A tabela 18 apresenta os resultados dos melhores ajustamentos para as relações entre os preços da carne comercializada na região da Grande São Paulo e os preços da arroba do boi gordo produzido em regiões fora do estado de São Paulo. A maioria das 
regiões apresentam relação de causalidade, nos melhores modelos os efeitos da autocorrelação dos residuos foram eliminados, a única excessão é a região de Campo Grande, que não apresenta relação causal. Uma característica dessa região é a ausência de compradores de bois vinculados a frigorificos paulistas, não se pode atribuir exclusivamente a isso a ausencia de relação causal, mas isso é relevante.

Tabela 18: Resultados dos modelos com melhor ajuste do Testes Causalidade entre os preços da carne na Grande São Paulo e os Preços da arroba fora do Estado de São Paulo

\begin{tabular}{l|ccl}
\hline relação & defasagens & $\mathrm{Q}^{*}$ & $F^{* *}$ \\
\hline $\mathrm{P}_{\mathrm{car}} \rightarrow \mathrm{P}_{\mathrm{TL}}$ & 9 & $52,4901(0,3727)$ & $15,0467(0,000)$ \\
$\mathrm{P}_{\mathrm{car}} \rightarrow \mathrm{P}_{\mathrm{CG}}$ & 9 & $28,0580(0,8251)$ & $1,4430(0,1783)$ \\
$\mathrm{P}_{\mathrm{car}} \rightarrow \mathrm{P}_{\mathrm{TM}}$ & 3 & $42,0493(0,2253)$ & $34,8050(0,000)$ \\
$\mathrm{P}_{\mathrm{car}} \rightarrow \mathrm{P}_{\mathrm{GO}}$ & 5 & $42,8045(0,2021)$ & $37,2450(0,000)$
\end{tabular}

* entre parênteses, ao lado da estatística de Q, é apresentado nivel de significância.

** entre parênteses, ao lado do resultado do teste de F, é apresentado o nivel de significância.

$\mathrm{Na}$ tabela 19 estão os resultados dos modelos que apresentaram melhor ajustamento nos testes de causalidade entre os preços da carne em São Paulo e o preço da arroba de boi em regiões selecionadas de fora do estado, mas que são fornecedoras de carne ou de animais para o estado. Dos modelos relativos a região de Três Lagoas o que apresenta melhor ajustamento foi o com 9 defasagens. Trata-se de uma região que faz divisa com o estado de São Paulo. A outra região que faz limite com São Paulo é a região do Triângulo Mineiro, cujo preço também apresenta causalidade com os preços da 
carne na capital paulista. O melhor ajustamento é obtido com o modelo com três defasagens.

Os preços da arroba de boi no mercado de Campo Grande, de acordo com os resultados dos teste, não causam os preços do mercado de carne na região da grande São Paulo.

Os preços da arroba de boi no estado de Goiás apresentam uma relação de causalidade com os preços da carne em São Paulo. O modelo que apresentou melhor ajustamento foi o com cinco defasagens de ordem cinco.

Tabela 19: Resultados dos modelos com melhor ajuste do Testes Causalidade entre os preços da arroba fora do Estado de São Paulo e os preços da carne na Grande São Paulo

\begin{tabular}{l|cll}
\hline relação & defasagens & $\mathrm{Q}^{*}$ & $F^{* *}$ \\
\hline $\mathrm{P}_{\mathrm{TL}} \rightarrow \mathrm{P}_{\mathrm{car}}$ & 5 & $44,0009(0,1689)$ & $4,0689(0,0012)$ \\
$\mathrm{P}_{\mathrm{CG}} \rightarrow \mathrm{P}_{\mathrm{car}}$ & 4 & $29,0336(0,7883)$ & $1,3085(0,2712)$ \\
$\mathrm{P}_{\mathrm{TM}} \rightarrow \mathrm{P}_{\mathrm{car}}$ & 16 & $56,9243(0,0146)$ & $2,4619(0,0018)$ \\
$\mathrm{P}_{\mathrm{GO}} \rightarrow \mathrm{P}_{\mathrm{car}}$ & 9 & $59,9701(0,0073)$ & $2,1046(0,0282)$ \\
\hline
\end{tabular}

* entre parênteses, ao lado da estatística de $Q$, é apresentado nível de significância.

${ }^{* *}$ entre parênteses, ao lado do resultado do teste de $F$, é apresentado o nivel de significância.

Os preços da arroba de boi fora do estado de São Paulo apresentam relação causal (ver tabela 20) com os preços da carne em três casos: região de Três Lagoas, de Goiás e a região do Triângulo Mineiro. Destas regiões somente os resultados 
da região de Três Lagoas tiveram os efeitos da autocorrelação de resíduos eliminados (dentro do critério adotado).

Os preços da arroba de boi na região de Campo Grande, de acordo com os resultados do teste de $\mathrm{F}$, não causam os preços da carne na grande São Paulo (neste caso a autocorrelação dos resíduos foi eliminada). Das quatro regiões analisadas somente na região de Campo Grande não foram encontrados compradores de boi de frigoríficos paulistas. Esta pode ser uma das explicações para a inexistência de causalidade entre os preços destas regiões.

Tabela 20: Resultados dos modelos com melhor ajuste do Testes Causalidade entre o Indicador de preços da arroba e os Preços da arroba fora do Estado de São Paulo

\begin{tabular}{|c|c|c|c|}
\hline relação & defasagens & $Q^{*}$ & $F^{\star \star}$ \\
\hline $\mathrm{P}_{\text {ind }} \rightarrow \mathrm{P}_{\mathrm{TL}}$ & 7 & $38,5218(0,3561)$ & $23,5580(0,000)$ \\
\hline$P_{\text {ind }} \rightarrow P_{C G}$ & 2 & $32,6994(0,6263)$ & $59,4531(0,000)$ \\
\hline$P_{\text {ind }} \rightarrow P_{T M}$ & 3 & $36,5576(0,4427)$ & $42,6723(0,000)$ \\
\hline$P_{\text {ind }} \rightarrow P_{G O}$ & 5 & $34,1635(0,5561)$ & $31,7907(0,000)$ \\
\hline
\end{tabular}

O indicador de preços do boi gordo apresenta relação causal com as quatro regiões de fora do estado de São Paulo (ver tabela 21). Os resultados do teste de F são significativos em todos os casos, a um nível de significância menor que 0,10 de 
probabilidade. No entanto, os resultados da região do Triângulo Mineiro devem ser analisados com a ressalva de que não foi eliminada toda autocorrelação dos resíduos.

O mercado de carne bovina apresenta um nível elevado de relação de causalidade entre as regiões de produção e o maior mercado consumidor. Com exceção da região de Campo Grande, todas as demais regiões importantes de produção de boi no estado de São Paulo ou situadas no centro sul do país, são influenciadas pelo mercado de carne da grande São Paulo. No entanto, nem todas as regiões são capazes de influenciar o mercado de carne da região da grande São Paulo. A influência de cada mercado no preço da carne parece estar associado com a sua importância em termos de oferta de carcaça ou ainda com a sua tradição.

Nas relações entre os preços da arroba de animais, o estado de São Paulo exerce influencia nos preços da arroba de boi em todas as regiões selecionadas. O estado de São Paulo dispõe da maior capacidade de abate, necessitando de animais de fora do estado para completar as escalas diárias de abates de seus frigoríficos. A tabela 22 mostra que os preços da arroba de fora do estado apresentam relações causais com a média dos preços do estado. Os preços nas regiões situadas fora do estado ficam condicionados a existência de concorrência com os frigoríficos situados nessas regiões. 
Tabela 21: Resultados dos modelos com melhor ajuste do Testes Causalidade entre os preços da arroba fora do Estado de São Paulo e o Indicador de preços da arroba de boi

\begin{tabular}{l|ccl}
\hline relação & defasagens & $Q^{*}$ & $F^{* *}$ \\
\hline $\mathrm{P}_{\mathrm{TL}} \rightarrow \mathrm{P}_{\text {ind }}$ & 7 & $32,6408(0,6291)$ & $1,9984(0,0541)$ \\
$\mathrm{P}_{\mathrm{CG}} \rightarrow \mathrm{P}_{\text {ind }}$ & 2 & $32,9846(0,6127)$ & $7,7522(0,0004)$ \\
$\mathrm{P}_{\mathrm{TM}} \rightarrow \mathrm{P}_{\text {ind }}$ & 7 & $69,3829(0,0006)$ & $2,4204(0,0194)$ \\
$\mathrm{P}_{\mathrm{GO}} \rightarrow \mathrm{P}_{\text {ind }}$ & 16 & $34,1965(0,5545)$ & $2,3996(0,0025)$ \\
\hline
\end{tabular}

Os resultados apresentados neste trabalho evidenciam que existe no mercado de carne um elevado nivel de integração. Os preços da carne não se movem sem causar reações no mercado do boi em praticamente todas as regiões e também os preços da arroba do boi em regiões distantes não se movem sem causar efeitos no preço de carne na região da grande São Paulo, que no caso representa o maior mercado consumidor do país. As informações do mercado de carne fluem de maneira rápida.

As cotações do boi gordo tendem cada vez a ser mais próximas entre regiões separadas por divisas de estado. A eliminação de diferenças de preços está mais ligada ao fim de diferenças de regras de tributação e a melhoria do sistema de transporte. 


\section{Conclusão}

O presente estudo analisou o comportamento dos preços do boi gordo em diversas regiões do estado de São Paulo e áreas circunvizinhas. Analisou-se também a relação dos preços do boi e o preço da carne na capital paulista.

Os resultados em seu conjunto apontam para uma forte integração tanto entre regiōes produtoras de boi como entre os niveis de produção e atacado. Essa conclusão decorre das observações de forte causalidade bidirecional entre a maioria das regiões analisadas.

Isso significa que a maioria das regiões e mercados analisados tem dinamismo suficiente para iniciar alterações de preços face a fatores locais e que isso determina reajustes de preços praticamente em todas as demais regiões.

Esses resultados tornam-se especialmente importantes quando se tem em conta que os dados analisados referem-se a cotações diárias de preços de boi e de carne bovina. Ou seja, as influências bidirecionais se dão com bastante agilidade.

Verifica-se, pois, que as regiões consideradas operam, na realidade, como se fossem um único mercado integrado. É claro que prevalecem entre elas os efeitos dos custos de transporte, processamento e encargos fiscais. Todavia, parece prevalecer entre essas praças um sistema eficiente de "vasos comunicantes", ou seja, mesmo que 2 
regiões não comercializem diretamente entre si, seus preços estarão interligados se ambas comercializarem com uma terceira região.

Essa dinâmica apresentada pelo mercado do boi e da carne tem sido sua característica histórica. Tido como um ativo rentável, o boi é visto como parte de um "portfolio" onde participam imóveis, ouro, câmbio, etc. Todos mercados dinâmicos e sensiveis a eventos sócio-economicos e políticos. Mais recentemente, com 0 desenvolvimento dos meios de comunicação e de informática, a disseminação de informações ganhou em aceleração, resultando num sistema de mercados locais intensamente integrados como foi constatado nesta pesquisa.

Duas observações gerais podem ser feitas tendo em vista os resultados deste estudo.

Em primeiro lugar, não se deve confundir o dinamismo observado nos mercados estudados com eficiência e modernização. Na verdade, sabe-se que tanto a produção de animais para abate, como a atividade de abate propriamente dita, ainda são feitas predominantemente com técnicas atrasadas, sob formas administrativas pouco elaboradas. Resulta dai um produto nem sempre de boa qualidade. Há portanto, muito a ser feito ainda no sentido de reduzir perdas e melhorar a qualidade da carne bovina brasileira tendo em vista o consumidor nacional e estrangeiro. O que este estudo mostra é que, apesar da relativa ineficiência produtiva a cadeia de carne bovina, as transações comerciais são dinâmicas, no sentido de que as arbitragens ocorrem com grande rapidez. Este último aspecto caracteriza os chamados mercados eficientes. Ou seja, a cadeia de 
carne bovina associa-se ao mesmo tempo, uma relativa ineficiência produtiva a uma elevada eficiência de mercado.

Em segundo lugar, o fato dos mercados regionais se mostrarem dinâmicos e bem integrados favorece o desenvolvimento de modernas formas de comercialização, especialmente o mercado futuro. No Brasil e também no exterior a tendência de crescimento desse mercado tem sido significativa, mormente devido aos mecanismos de liquidação financeira, que dispensam a entrega física do produto. Esta entrega física, quando o produto é heterogêneo, tem sido fator de inibição dos mercados. As liquidações financeiras, ao dispensar a entrega física, tem dado mais segurança e liquidez ao mercado de futuros.

A liquidação financeira de contratos de futuros tem que se basear em um índice de preço médio do mercado para as regiões de produção, o que em muito casos tem dificultado o emprego desses mecanismos. No caso do boi gordo analisado neste estudo, fica claro que a elaboração daquele índice é viável no sentido de que se pode obter uma média de preços bem representativa das relações havidas entre preços locais (nas diversas praças que se negocia o boi gordo) bem como do preço no atacado.

Isto significa que tanto os produtores de boi, como os frigoríficos e atacadistas podem ter no mercado futuro de boi gordo um instrumento eficaz para a administração do risco de suas operações comerciais. 


\section{Referências Bibliográficas}

ADABO, J.H. Tendências das margens de comercialização da carne bovina em São Paulo, 1978.

AGUIAR, D.R.D. Formação de Preços na Indústria Brasileira de Soja - 1982/1989. Piracicaba, 1990. (Mestrado - ESALQ/USP)

ANUÁRIO ESTATÍSTICO DO IBGE. Rio de Janeiro, FIBGE, Brasil, n.1,1993.

BACCHI, M.R.P. Comercialização e Transmissão de Preços da Carne de Frango no Estado de São Paulo. Piracicaba 1990. (Mestrado - ESALQ/ USP)

BACCHI, M.R.P. Previsão de Preços de Bovino, Suíno e Frango com Modelos de Séries Temporais. Piracicaba 1994. (Doutorado - Escola Superior de Agricultura "Luiz de Queiroz"/ USP)

BAILEY, D.V.; BRORSEN, B. W. Dynamics of Regional Fed Cattle Prices. Western Journal Economics, 10(1): 126-133, july, 1985. 
BARROS, G.S.C. Transmissão de preços pela central de abastecimento de São Paulo, Brasil. Revista Brasileira de Economia, Rio de Janeiro, 44(1):5-20, jan./mar. 1990.

BARROS, G.S.C. Economia da Comercialização Agrícola. Piracicaba: FEALQ, 1987. $306 \mathrm{p}$.

BARROS, G. S. C. et alii. Relatório de Pesquisa: ïndice de Preços do Boi Gordo e do Bezzerro. FEALQ, 1994.

BLISKA, F.M.M. Transmissão de Preços de Carne Bovina entre os niveis de Mercado: uma aplicação do modelo de Auto_Regressão Vetorial. 1989. (Mestrado - ESALQ/ USP)

BRORSEN, W. B.; CHAVAS, J.P.; GRAND, W.R.; NGENGE, A.W. Spatial and tempora relationships among selected U.S. markets. North Central Journal of Agricultural Economic. 7(1).1-10. Jan. 1985.

CANTO, W.L. Estudos Econômicos - Alimentos Processados. Campinas. Brasil, 1986.

COUTO, M.T. Modelos estruturais de séries temporais: o caso dos preços da bovinocultura de corte no estado de São Paulo , 1996. ( Mestrado - ESALQ/USP) 
DIAS, G.L.S. Avaliação da Política Econômica para a Pecuária de Corte no Brasil. 1972. (Doutoramento - FEA/USP)

FERREIRA, A. H. B. Testes de Granger-causalidade para a balança comercial brasileira. Revista Brasileira de Economia, 47(1): 83-95, jan./mar 1993.

GUIMARÃES, V.D.A. Comercialização e Transmissão de Preços de Carne de Frango no Estado de São Paulo. 1990. ( Mestrado - ESALQ/ USP)

HASEGAWA, M.M. O mercado de reposição da pecuária bovina de corte no estado de São Paulo. 1996. ( Mestrado - ESALQ/USP)

HOFFMANN, H.; VIEIRA, S. Análise de Regressão: uma introdução à econometria. São Paulo: HUCITEC/EDUSP, 1977. 339 p.

KMENTA, J. Elementos de Econometria - Teoria estatística Básica. 2 ed. São Paulo: Atlas, 1988. $2 \mathrm{v}$.

LATTIMORE, R.G. An econometric study of the brazilian beff sector. W. Lafayette, 1974, $177 p$ ( Ph.D. Prudue University) 
LícıO, A.M.A., !994. A Tributação na Agricultura Brasileira. Brasília. IPEA - Estudos de Política Agrícola. Relatório de Pesquisas-7.

LONGO, C.A., 1986. Caminhos para a Reforma Tributária. Estudos Econômicos FIPE/Pioneira.

MAKRIDAKIS, S. A survey of time series. International Statistical Review, Voorburg - NE, 44(1): $29-70,1976$.

MARQUES, P.V.; AGUIAR, D.R.D. Comercialização de Produtos Agrícolas. São Paulo: EDUSP, 1993. (Coleção Campi, 13)

MASCOLO, J.L. Um estudo econométrico da pecuária de corte na Brasil. Revista Brasileira de Economia, Rio de Janeiro, 33(1):65-105, jan/mar. 1979.

MONTEMURRO, L.E.P. Fatores condicionantes do comportamento do setor pecuário no Uruguai, 1979. ( Mestrado - ESALQ/USP ).

MULLER, C.C. O ciclo do gado e as tentativas governamentais de controle do preço da carne. Estudos Econômicos, 17(3):435-456, set/dez. 1987.

PEIXOTO, A.M. et alii, 1993. Bovinocultura de Corte: Fundamentos da Exploração Racional. In : PEIXOTO, A.M.; MOURA, J.C.; FARIA, V.P. Bovinocultura de Corte. 2ed. Piracicaba: FEALQ, 1993. 
Regulamento do ICMS. 1991. Secretaria de Estado da Fazenda. São Paulo.

SCHROEDER, T.C. GOODWIN, B.K. Regional fed cattle price dinamics. Wertern Journal of Agricultural Economics, 15(1): 111-122, jul.1990.

SPREEN, T. H.; SHONKWILER, J.S. Causal relationships in the fed cattle markert. Southern Journal of Economics, 149-153, july. 1981.

UEDA, E.; TORRES, I. Estrutura Tributária Estadual: potencialidades, adequação e reforma. São Paulo. Instituto de Pesquisas Economicas da Universidade de São Paulo. 1984.

TORRES, I., 1982. ICM: adequação e transferência de receita.São Paulo. Instituto de Pesquisas Economicas da Universidade de São Paulo.

ZIMMER, A.H.; Pastagens para boivinos de corte. In: PEIXOTO, A.M.; MOURA, J.C.; FARIA, V.P. Bovinocultura de Corte. 2ed. Piracicaba: FEALQ, 1993. (Série atualização em zootecnia, 8). 